\title{
EL DIÁLOGO JURISDICCIONAL TRAS LA SENTENCIA DEL TJUE M.A.S. Y M.B.: ENTRE ESTÁNDAR EUROPEO DE PROTECCIÓN Y TENDENCIAS CENTRÍPETAS
}

\author{
VALENTINA FAGGIANI' \\ Universidad de Granada \\ valenf@ugr.es
}

\author{
Cómo citar/Citation \\ Faggiani, V. (2018) \\ El diálogo jurisdiccional tras la sentencia del TJUE M.A.S. y M.B.: \\ entre estándar europeo de protección y tendencias centrípetas. \\ Revista de Derecho Comunitario Europeo, 60, 639-676. \\ doi: https://doi.org/10.18042/cepc/rdce.60.05
}

\section{Resumen}

El presente trabajo analiza las principales cuestiones a las que la Sentencia del Tribunal de Justicia dictada en los asuntos M.A.S. y M.B. no ha dado solución y los posibles escenarios que abre en el espacio europeo de justicia penal. Por esto, tras un análisis de la tensión constante, que caracteriza la saga Taricco, entre identidades nacionales y primacía del derecho de la UE, se profundiza en la supuesta nueva naturaleza procesal de la prescripción tras la directiva PIF, en la legalidad penal como límite a la primacía del derecho UE, en cuanto principio general fruto de las tradiciones constitucionales comunes a los Estados miembros, y en la actitud centrípeta de la Corte costituzionale italiana.

1 Profesora ayudante doctora de Derecho Constitucional de la Universidad de Granada. Este estudio ha sido realizado en el ámbito del grupo de investigación «Andalucía, la Unión Europea y el Estado social» (SEJ-106), y del proyecto de investigación «Los derechos fundamentales ante las crisis económicas y de seguridad en un marco constitucional fragmentado» (DER 2016-77924P). 


\section{Palabras clave}

STJUE, M.A.S. y M.B.; saga Taricco; primacía; identidades nacionales; principio de legalidad penal; diálogo jurisdiccional europeo.

\section{THE JURISDICTIONAL DIALOGUE AFTER ECJ'S JUDGMENT IN M.A.S. AND M.B.: BETWEEN EUROPEAN STANDARD OF PROTECTION AND CENTRIPETAL TRENDS}

\section{Abstract}

The present paper analyzes the main issues to which the CJEU judgment in M.A.S. and M.B. has not given solution and the possible scenarios that it opens in the European space of criminal justice. After an analysis of the constant tension in the Taricco saga between national identities and the primacy of EU law, it will deepen the alleged new procedural nature of the prescription after the PIF Directive, the principle of criminal legality as a limit to the primacy of EU law, and the centripetal attitude of the Italian Constitutional Court.

\section{Keywords}

CJEU, M.A.S. and M.B.; Taricco saga; primacy; national identities; principle of criminal legality; European jurisdictional dialogue.

\section{LE DIALOGUE JURISPRUDENTIEL À TRAVERS L'ARRÊT CJUE M.A.S. ET M.B.: ENTRE STANDARD EUROPÉEN DE PROTECTION ET TENDENCES CENTRIPÈTES}

\section{Résumé}

Le présent travail analyse les principales questions auxquelles l'arrêt M.A.S. et $M . B$. de la Cour de justice n'a pas donné de solution et les différents scenarios qu'il ouvre dans l'espace européen de justice pénale. À travers une analyse de la tension constante —caractéristique de la «saga Taricco»— entre identités nationales et primauté du droit de l'Union, notre étude va approfondir deux aspects: la légalité pénale issue des traditions constitutionnelles communes aux États membres comme limite au principe de primauté et l'attitude dissonante adoptée par la Cour constitutionnelle italienne.

\section{Mots clés}

CJUE, M.A.S. et M.B.; Taricco saga; primauté; identités nationales; principe de légalité pénale; dialogue juridictionnel européen. 


\section{SUMARIO}

I. LA «SAGA» TARICCO: ENTRE IDENTIDADES NACIONALES Y PRIMACÍA. II. LA APLICACIÓN TÁCITA DE LOS CONTRALÍMITES POR PARTE DEL TJUE. III. ¿̇LA NATURALEZA PROCESAL DE LA PRESCRIPCIÓN TRAS LA DIRECTIVA PIF? IV. EL PRINCIPIO DE LEGALIDAD PENAL COMO LÍMITE A LA PRIMACÍA DEL DERECHO UE. V. LA ACTITUD CENTRÍPETA DE LA CORTE COSTITUZIONALE. VI. ALGUNAS REFLEXIONES EN TORNO AL ASUNTO TARICCO. BIBLIOGRAFIA.

\section{LA «SAGA» TARICCO: ENTRE IDENTIDADES NACIONALES Y PRIMACÍA}

La denominada «saga Taricco» ${ }^{2}$ se enmarca en la reciente tendencia de los tribunales constitucionales de los Estados miembros de la UE a invocar los

2 Esta «saga» empezó con la sentencia del Tribunal de Justicia de la Unión Europea (en adelante TJUE) de 8 de septiembre de 2015, Taricco y otros, C-105/14, EU:C: 2015:555 (en adelante Taricco I), en la que se afirmó la incompatibilidad de la normativa italiana relativa a la interrupción y los plazos máximos de prescripción de los delitos con el principio fundamental del deber de cooperación leal (art. 4, apdo. 3, TUE) porque era incapaz de tutelar de forma suficientemente adecuada los intereses financieros de la Unión. El Sr. Taricco y las demás personas implicadas en el procedimiento principal fueron imputadas de haber constituido y organizado entre 2005 y 2009 una asociación ilícita para delinquir, sirviéndose del esquema denominado «carrusel del IVA». La sistemática evasión del impuesto sobre el valor añadido habría creado una distorsión en la libre competencia entre las empresas que operan en el sector, permitiendo a los imputados vender la propia mercancía (botellas de champán) a precios muy inferiores respecto a la media de mercado. Una parte de los delitos contestados ya se había extinguido porque estaban prescritos; los demás, en cambio, hubieran prescrito el 8 de febrero de 2018. El Tribunal de Cuneo, considerando dicho plazo insuficiente para adoptar una sentencia irrevocable, decidió dirigirse en vía prejudicial al TJUE (17 de enero de 2014). De esta forma, se intentaba poner fin a una situación de sistemática impunidad de hecho, por otra parte perjudicial tanto para los intereses financieros del erario italiano como para aquellos de la UE. La normativa italiana en materia de prescripción prevé una prórroga del plazo máximo solo hasta un cuarto, que en la mayoría de los casos no permite adoptar un pronunciamiento 
principios supremos del ordenamiento nacional frente a la primacía absoluta o incondicionada del derecho de la Unión. Esta tendencia es el resultado de la cada vez mayor interacción que caracteriza la dimensión multilevel y de la consiguiente necesidad de aclarar cuáles son los principios fundamentales constituyentes del núcleo duro del patrimonio constitucional nacional y, sobre todo, hasta qué punto la UE puede incidir en ellos ${ }^{3}$.

definitivo por la complejidad de las investigaciones y la gravedad de tales crímenes. El TJUE, en la sentencia Taricco I, afirmó que las disposiciones controvertidas del Código Penal (arts. 160 y 161 del Código Penal italiano) podían ser contrarias a las obligaciones derivadas del art. 325 TFUE, apdos. 1 y 2, para los Estados miembros, cuando dichas disposiciones impidan imponer sanciones efectivas y disuasorias en un número considerable de casos de fraude grave que afecten a los intereses financieros de la Unión o establezcan en el caso de fraudes que perjudiquen los intereses financieros del Estado miembro de que se trate plazos de prescripción más largos que en el caso de fraudes que afecten a los intereses financieros de la Unión. El Tribunal de Justicia declaró también que corresponde al órgano jurisdiccional nacional competente garantizar la plena eficacia del art. 325 TFUE, apdos. 1 y 2, dejando si es preciso sin aplicación las disposiciones del derecho nacional que impidan al Estado miembro de que se trata dar cumplimiento a las obligaciones que le imponen las mencionadas disposiciones del TFUE.

3 Tras la entrada en vigor del Tratado de Lisboa, se ha desarrollado la tendencia de los tribunales constitucionales y de los tribunales de última instancia de los Estados miembros de la UE a invocar los principios supremos del ordenamiento interno para oponerse a la primacía absoluta del derecho de la UE. El Tribunal constitucional checo, en el caso relativo a las pensiones eslovacas declaró ultra vires la sentencia del TJUE, C-399/09, Landtovà, 22.06.2011 (Czech Constitutional Court, n. Pl. ÚS 5/12, Slovak Pensions XVII, 31.01.2012). A continuación, el Tribunal constitucional español (en adelante TC) en la sentencia 26/2014, de 13 de febrero, en el ámbito del caso Melloni, aunque no aplicó el art. 24.2 CE como contralímite, antes de incorporar el estándar fijado por el TJUE, mencionó la declaración del TC 1/2004, de 13 de diciembre, condicionando hasta tres veces la primacía del derecho de la UE al respeto de los límites materiales a la integración, es decir a los principios y valores fundamentales de la Constitución. Poco después, también el Tribunal Constitucional Federal Alemán, tanto en la sentencia sobre el caso del Sr. R, de 15 de diciembre de 2015, que tenía por objeto la ejecución de una orden europea de detención en el marco de una sentencia de condena pronunciada in absentia, como en la sentencia de 26 de junio de 2016 (BVerfG, 2 BvR 2728/13, 21.06.2016), que cierra la «saga» OMT/ Gauweiler, no aplicó los contra-límites pero los invocó, exhortando al TJUE a respetar los principios que constituyen el núcleo duro de la identidad constitucional nacional. Por su parte, el Tribunal Constitucional de Hungría, en la sentencia 22/2016, de 16 de diciembre de 2016, relativa a la obligación de este país de respetar el plan de cuotas 
En este sentido, el caso Taricco ha hecho aún más evidente la necesidad de alcanzar un punto de encuentro en el «diálogo jurisdiccional» entre la dimensión europea y la dimensión nacional del principio de legalidad penal y sus corolarios, entre primacía del derecho de la UE e identidades constitucionales nacionales y, más en general, entre «derechos constitucionales» (especialmente, en el caso de que se trata, los derechos procesales) y «derechos eurofundamentales», tal y como han sido reconocidos en la Carta.

Sin embargo, el asunto Taricco es más y de hecho no se debería creer que con la sentencia M.A.S. y M.B. ${ }^{4}$ y la respuesta contextual de la Corte costituzionale dicha saga haya llegado al epílogo; ni que ya se hayan resuelto los problemas aplicativos de la normativa italiana controvertida en materia de prescripción; ni que las dos Cortes (TJUE y Corte costituzionale) estén ahora dispuestas a vivir felices y en armonía.

Por todo ello, el presente trabajo, tras analizar someramente los puntos más relevantes, que han caracterizado la evolución de dicha «saga», se centrará en las principales cuestiones a las que la sentencia M.A.S. y M.B. no ha dado solución y en los posibles escenarios que abre en el espacio europeo de justicia penal.

La Corte costituzionale italiana, como es sabido, tras los juicios incidentales de legitimidad interpuestos por el Tribunal de Apelación de Milán ${ }^{5}$

para el reparto equitativo de los solicitantes de asilo entre los Estados miembros, hizo referencia explícita a las decisiones Solange-Maastricht-Lissabon, [Decision 22/2016 (XII.5), AB on the Interpretation of Article E) (2) of the Fundamental Law (Const. Ct. Hung. Nov. 30, 2016)]. En dicho pronunciamiento, el Tribunal constitucional de Hungría dejó claro que la tutela de la identidad constitucional no puede ser puesta en discusión por las exigencias de la integración europea y afirmó la propia competencia a examinar si el ejercicio conjunto con otros Estados miembros a través de las instituciones de la UE de las competencia art. E) (2) de la Ley Fundamental de Hungría, que contiene la cláusula de apertura de este País a la UE, viola o no la dignidad humana, otros derechos fundamentales, la soberanía de Hungría o su identidad constitucional. Y por último, el Tribunal Supremo danés, con sentencia 15/2014, de 6 de diciembre, rechazó dar actuación a la sentencia del TJUE de 19 de abril de 2016, Dansk Industri, C-441/14, EU:C:2016:278, considerando que viola el reparto de competencias fijado en la Ley danesa de adhesión a la UE. Para un cuadro general de esta tendencia, véase Faraguna (2016: 197-254), Anzon Demming (2017: 1-23) y Faggiani (2017a).

4 Sentencia del Tribunal de Justicia de 5 de diciembre de 2017, M.A.S. y M.B., C-42/17, EU:C:2017:936.

5 Corte di Appello di Milano, sezione II penale, ordinanza (infra ord./auto) $\mathrm{n}$. 339/2015, del 18 maggio. Al respecto, se reenvía a Viganò (2015a). 
y el Tribunal de Casación ${ }^{6}$ sobre la Ley 130/2008, de ratificación y ejecución del Tratado de Lisboa ${ }^{7}$, en relación con la interpretación del art. 325 TFUE $^{8}$, realizada en la sentencia Taricco $I^{9}$, tuvo que enfrentarse al difícil dilema de si conformarse al decisum del TJUE u oponerse a la primacía del derecho de la

6 Cass., sez. III pen., ord. n. 28346/2016, dep. 8.7.2016. El 2 de febrero de 2017 también el Tribunal de Siracusa interpuso otra cuestión de inconstitucionalidad parecida a la Corte Costituzionale (Tribunale di Siracusa, ord., 2.02.2017). Según los mencionados órganos jurisdiccionales, la solución del TJUE en la sentencia Taricco I sería incompatible no solo con el principio de legalidad en materia penal (art. 25.2 Constitución italiana, en adelante Const. it.) y, en particular, con sus corolarios de la reserva de ley y de la prohibición de aplicación retroactiva, sino también con el principio de igualdad (art. 3 Const. it.), el derecho a la tutela judicial efectiva (art. 24 Const. it.), el principio de división de poderes entre poder legislativo y judicial (art. 101.2 Const. it.), la función reeducativa de la pena y los principios de culpabilidad y de proporcionalidad entre el delito cometido y la pena (art. 27.3 Const. it.) y, por último, con la cláusula que legitima las limitaciones de la soberanía derivadas de la pertenencia de Italia a organizaciones internacionales supranacionales (art. 11 Const. it.). Tales «parámetros de constitucionalidad», como afirmado por la Cassazione penale, sezione III, ord. n. 28346/2016, cit., cons. in dir. n. 4.1., serían «talmente avvinti al "nucleo essenziale" della legalità» que no pueden no ser considerados desde una perspectiva sistemática en su conjunto.

7 Legge 2 agosto 2008, n. 130, Ratifica ed esecuzione del Trattato di Lisbona che modifica il Trattato sull'Unione europea e il Trattato che istituisce la Comunità europea e alcuni atti connessi, con atto finale, protocolli e dichiarazioni, fatto a Lisbona il 13 dicembre 2007 (GU Serie Generale n. 185 del 8.8.2008 — Suppl. Ordinario n. 188).

8 Según el art. 325 TFUE, «la Unión y los Estados miembros combatirán el fraude y toda actividad ilegal que afecte a los intereses financieros de la Unión mediante medidas que deberán tener un efecto disuasorio y ser capaces de ofrecer una protección eficaz en los Estados miembros y en las instituciones, órganos y organismos de la Unión» (primer apdo.). Tales medidas deberán asegurar que el sistema de protección instituido para combatir el fraude que afecte a los intereses financieros de la UE sea equivalente a aquello de los Estados miembros (segundo apdo.). Esta disposición, a pesar de no haber sido invocada por el juez del reenvío, había sido introducida por la abogado general Kokott, que la consideró determinante para resolver la cuestión prejudicial (conclusiones de la abogado general Kokott, Taricco y otros, C-105/14, presentadas el 30 de abril de 2015, EU:C:2015:293, punto 74 y ss.).

9 La doctrina (sobre todo italiana) respecto de la sentencia Taricco I es muy amplia. Sin pretensiones de exhaustividad, ex multis, véase: Amalfitano (2015: 1-8); Civello (2015: 2-17); Eusebi (2015: 1-8); Rossi (2015: 1564-1571); Salcuni (2015: 1-15); Sarmiento Ramírez (2015); Bassini (2016: 94-113); Bin (2016: 1-9); Faggiani (2016: 509-532); Luciani (2016: 1-20); Lupo (2016: 1-15); Maiello (2016: 1250-1259); 
UE, aplicando — como le había pedido también la doctrina italiana más autorizada (ex multis Luciani, 2016) ${ }^{10}$ - los contralímites ante la violación del principio de legalidad en materia penal (art. 25.2 Const. it.) ${ }^{11}$.

La reacción/oposición de los jueces italianos y de la doctrina a la sentencia Taricco I indujo a la Corte costituzionale a procrastinar su intervención y a someter con auto 24/2017, de 27 de enero, un inesperado reenvío prejudicial al TJUE ${ }^{12}$, en el que le solicitaba, en el ámbito de un procedimiento de urgencia, resolver los puntos más críticos de este pronunciamiento y adoptar una solución de compromiso entre las obligaciones impuestas por la pertenencia de Italia a la UE y los principios estructurales de su ordenamiento interno.

Un paso, sin duda, "estratégico» (Faggiani, 2017b) ${ }^{13}$ del que se deduce su propensión al diálogo y a la colaboración leal, pero con una "pieza de un

Manes (2016: 1-26); Marcolini (2016: 362-374); Viganò (2015b: 1-16); Viganó (2016: 1-35); y Bernardi (2017).

$10 \mathrm{Al}$ respecto, Luciani (2016: 17 y 18), considera que: «Al di là di eventuali ostacoli processuali, vi sono tutte le condizioni perché il vento cambi: a) siamo a un punto bassissimo del consenso nei confronti del progetto di integrazione europea, che può essere risollevato solo imprimendo una sterzata al perdurante economicismo dell'Unione, novellamente palesatosi in Taricco; b) la sentenza violativa dei controlimiti è talmente discutibile che opporvisi sarebbe semplicemente un atto di civiltà giuridica; c) la Corte di giustizia non ha mostrato la minima considerazione per la Corte costituzionale italiana, la quale, non foss'altro per tutelare la propria dignità, potrebbe e dovrebbe reagire; d) vera l'interpretazione dell'art. 4.2 del TUE che sopra si è avanzata, la Corte costituzionale non dovrebbe temere di innescare una 'guerra' con la Corte di giustizia, per la semplice ragione che anche ai sensi di un diritto europeo rettamente interpretato è sua competenza la determinazione dei tratti identitari del nostro ordinamento: chi vorrebbe tenere i controlimiti sempre in soffitta agita lo spauracchio di chissà quali catastrofi, ma una Corte costituzionale autorevole come la nostra non ha motivo di farsene spaventare. Le ragioni della tutela dei diritti della persona e la "ragion di Stato”, per una volta, coincidono e, unite, cospirano nel senso della cancellazione della grave anomalia che la sentenza della Corte di giustizia ha determinato». En cambio, realiza un eficaz y exhaustivo análisis de los «costes» de una decisión en este sentido Viganò (2016: 4 y ss.).

11 Según el art. 25.2 Const.it.: «Nessuno può essere punito se non in forza di una legge che sia entrata in vigore prima del fatto commesso".

12 Corte cost., ord. n. 24/2017, dep. 26.01.2017. Se trataría del tercer reenvío prejudicial interpuesto por la Corte Costituzionale al TJUE. El primero fue presentado con ord. $\mathrm{n}$. 103/2008, dep. 15.04.2008, en el ámbito de un juicio en vía principal, y el segundo con ord. n. 207/2013, dep. 18.07.2013, en el ámbito de un juicio en vía incidental.

13 Con respecto al reenvío prejudicial de la Corte Costituzionale, véase también Amalfitano (2017); Bassini y Pollicino (2017); Bernardi y Cupelli (2017); Cupelli (2017: 
proceso de resistencia al proceso de integración europea» (en italiano: «tassello di un processo di resistenza al processo di integrazione europea»; Montanari, 2018: 16). La Corte costituzionale hizo su último intento para no llegar a utilizar el arma de los contralímites en el auto 24/2017. A través del instrumento del reenvío prejudicial, manifestó la deferencia hacia la primacía del derecho de la UE, para reiterar su posición de garante supremo de los principios constituyentes del núcleo duro de la identidad nacional. De hecho, dejó claro que no estaba dispuesta a bajar a compromisos sobre los principios fundamentales del ordenamiento nacional, como el principio de legalidad en materia penal.

Esto le ha permitido evitar el enfrentamiento directo y abierto, derivado de la aplicación inmediata del contralímite ex art. 25.2 Const. it. y de la consiguiente declaración de ilegitimidad constitucional de la Ley de ratificación y ejecución del Tratado de Lisboa. De esta forma, la Corte costituzionale, remitiendo con un ultimátum (Ruggeri, 2017a) la solución del caso Taricco y su impacto en el ordenamiento italiano y, más en general, en el proceso de integración europea al TJUE, le pedía que elaborara una respuesta alternativa para explicar los aspectos más controvertidos de este pronunciamiento y dar una interpretación más acorde a los principios estructurales del ordenamiento italiano $^{14}$.

De lo contrario, se hubiera visto obligada a oponerse a la primacía del derecho de la UE. En este sentido, la Corte costituzionale, en el auto 24/2017, afirmó tajantemente que, aunque la primacía del derecho de la Unión resida en el art. 11 Const. it. ${ }^{15}$, su aplicación en el ordenamiento italiano está

199-244); Faraguna (2017); Guazzarotti (2017); Kostoris (2017: 1-15); Luciani (2017: 1-11); Manes (2017: 1-26); Repetto (2017); Ruggeri (2017a: 81-88); y Tega, 2017.

14 Sarmiento Ramírez Escudero (2018: 3) distingue la actitud de la Corte costituzionale de la del Tribunal Constitucional Federal Alemán: «Second, the Corte Costituzionale chose a transparent but non-confrontational strategy. In stark contrast with the German Constitutional Court's preliminary reference in the OMT case, a hawkish and aggressive reference which even threatened to set aside Luxembourg's judgment if necessary, the Italian court chose to point at the alternatives in the hands of the Court of Justice, refusing at all times to warn of the consequences of a response in the negative».

15 El art. 11 Const. it. dispone que: «L'Italia ripudia la guerra come strumento di offesa alla libertà degli altri popoli e come mezzo di risoluzione delle controversie internazionali; consente, in condizioni di parità con gli altri Stati, alle limitazioni di sovranità necessarie ad un ordinamento che assicuri la pace e la giustizia fra le Nazioni; promuove e favorisce le organizzazioni internazionali rivolte a tale scopo». Y el art. 117.1 Const. it. además prevé que: «La potestà legislativa è esercitata dallo Stato e dalle 
condicionada al respeto de los principios y los derechos inalienables de la persona reconocidos en la Constitución (art. 2) ${ }^{16}$.

Tres son los perfiles de incompatibilidad con el ordenamiento italiano invocados en el auto 24/2017: a) el principio de determinación, b) el carácter sustantivo del instituto de la prescripción en el ordenamiento italiano, y c) los principios supremos del orden constitucional, los derechos inalienables de la persona reconocidos por la Constitución y los principios análogos contenidos en la Carta de los Derechos Fundamentales de la UE y los derivados de las tradiciones constitucionales comunes.

Ahora bien, según la Corte costituzionale, en el supuesto de que se trata, el TJUE tenía que modificar dicha sentencia. La obligación derivada de la doctrina Taricco I de no aplicar la normativa italiana "controvertida" (arts. 160, último apdo., y 161, apdo. segundo, del Código Penal italiano), que establece el techo máximo de prescripción de los delitos en presencia de actos de interrupción, por un lado, sería contrario a la naturaleza sustantiva de este instituto en el ordenamiento jurídico italiano, la cual implica que tales normas sean razonablemente previsibles para los justiciables en el momento de la comisión de las infracciones que se les imputan sin que puedan ser modificadas in peius con carácter retroactivo; y por otro, contrastaría con la exigencia de que toda normativa nacional relativa al régimen de imputación debe estar fundamentada en una base legal suficientemente precisa para poder delimitar $\mathrm{y}$ orientar la apreciación del juez nacional ${ }^{17}$.

Las conclusiones del abogado general Y. Bot, en el caso M.A.S. y M.B., de 18 de julio de $2017^{18}$, en las que se invitaba al TJUE a mantener una «conducta no colaborativa» (Bin, 2017: 1), no modificando la doctrina Taricco I, no dejaban prever un cambio jurisprudencial. El abogado Y. Bot, con una actitud de desafío, consideraba que la República Italiana no habría tenido que activar los contralímites, puesto que la aplicación de un plazo de prescripción más largo, derivado de la obligación establecida en la sentencia Taricco I del TJUE, no violaría la identidad constitucional nacional (art. 4.2 TUE) ${ }^{19}$.

Regioni nel rispetto della Costituzione, nonché dei vincoli derivanti dall'ordinamento comunitario e dagli obblighi internazionali».

16 Corte costituzionale, ord. n. 24/2017, cit., cons. in dir. n. 2, que remite a las siguientes sentencias de la Corte costituzionale: 232/1989, dep. 21.4.1989; 170/1984, dep. 8.06.1984; y 183/1973, dep. 27.12.1973.

17 Sentencia M.A.S. y M.B., cit., apdo. 27.

18 Conclusiones del abogado general Bot, M.A.S. y M.B., C-42/17, EU:C:2017:564.

19 Conclusiones, M.A.S. y M.B., cit., puntos 169-187, en los que se ocupa expresamente de la cuestión relativa al respeto de la identidad constitucional de la República Italiana. Al respecto, véase Bin (2017). 
El principio de legalidad de los delitos y las penas, no estando incluido en los arts. 1 a 12 de la Const. it., sino en el art. 25 Const. it., a priori no sería, en su opinión, un principio «fundamental». Esta lectura de la Constitución italiana, sin embargo, no es correcta e incluso podría ser peligrosa (Faggiani, 2017a: 125). No se pueden excluir de los principios fundamentales del sistema jurídico italiano los derechos de la persona porque están reconocidos en la parte primera de la Constitución. Su carácter fundamental no solo es indiscutible en un Estado constitucional de derecho, siendo el reconocimiento y la protección de estos uno de sus elementos constitutivos, sino que además el art. 2 de la Const. it. los califica de «inviolables» y la jurisprudencia constante de la Corte costituzionale se expresa en el mismo sentido ${ }^{20}$.

20 Ni parece convencer la referencia en las conclusiones del abogado general Bot, asunto M.A.S. y M.B., cit., a la sentencia de la Corte Costituzionale núm. 18/82, de 2 de febrero de 1982, apdo. 4, sobre el derecho a la tutela judicial efectiva en la que afirmó que solo «el «núcleo duro» de un principio fundamental puede justificar la aplicación de los contralímites, excluyendo las diferentes instituciones jurídicas en las que este derecho puede manifestarse concretamente y evolucionar a lo largo de la historia y en función de las exigencias de esta última (apdo. 183). Y tampoco satisface la referencia a la sentencia de la Corte costituzionale núm. 238/2014 sobre la ejecución del pronunciamiento del Tribunal Internacional de Justicia de 3 de febrero de 2012 sobre crímenes de guerra (CIG, Judgment of 3 February 2012, Jurisdictional immunities of the state, Germany v. Italy: Greece intervening), en la que la Corte Costituzionale aplicó por primera vez los contralímites. En este pronunciamiento, la Corte costituzionale no solo se opuso a la aplicación de una norma de derecho internacional consuetudinario lesiva de uno de los principios fundamentales del ordenamiento estatal (el derecho a la tutela judicial efectiva ex art. 24 Const. it.), sino que elaboró una reconstrucción sistemática y jurisprudencial de esta emblemática categoría, ofreciendo por primera vez una definición en la que intenta considerar la pluralidad de ordenamientos que componen el sistema (internacional, europeo, concordatario y nacional). Al respecto, véase Corte costituzionale, sent. n. 238/2014, 22.10.2014, punto 3.2 del Considerato in diritto. A este propósito es interesante observar que la Corte costituzionale ha reiterado que los principios supremos del sistema constitucional y los derechos inalienables de la persona constituyen un límite para el ingreso de las normas internacionales generalmente reconocidas a las que el ordenamiento jurídico italiano se conforma, en virtud del art. 10.1 Const. it., y operan como contralímite a las normas del derecho de la UE y a las normas de ejecución de los Pactos Lateranenses y del Concordato. Estos elementos identificativos e irrenunciables del ordenamiento constitucional serían, por lo tanto, sustraídos también a la revisión constitucional (arts. 138 y 139 Const. it.). Sobre este pronunciamiento ex multis véase: Dickmann (2014: 1-22); Faraguna (2014: 1-4); Ruggeri (2014: 1-11); Calvano (2016: 1-19). 
Sin embargo, el TJUE, inesperadamente, en la sentencia de 5 de diciembre de 2017, en el ámbito del procedimiento penal a cargo de M.A.S. y M.B., se ha alejado de la interpretación del abogado general. El Tribunal de Luxemburgo, adoptando una decisión aparentemente «salomónica» (Viganò, 2018: 2), ha completado la doctrina Taricco I y la ha adaptado a las peticiones de la Corte costituzionale. La sentencia Taricco II establece una excepción al aplicar que la obligación para el juez nacional, ex art. 325 TFUE, apdos 1 y 2, de no aplicar, en el marco de un procedimiento penal que se refiere a infracciones relativas al impuesto sobre el valor añadido, disposiciones internas en materia de prescripción comprendidas en el derecho material nacional que impiden la imposición de sanciones penales efectivas y disuasorias en un número considerable de casos de fraude grave que afecten a los intereses financieros de la Unión Europea o que establecen en el caso de fraudes que perjudiquen dichos intereses plazos de prescripción más cortos que en el caso de fraudes que afecten aquellos del Estados miembro de que se trate, deja de existir cuando dicha inaplicación produzca una violación del principio de legalidad de los delitos y las penas, debido a la falta de precisión de la ley aplicable o a la aplicación retroactiva de una legislación que impone condiciones de exigencia de responsabilidad penal más severas que las vigentes en el momento de la comisión de la infracción.

Del dispositivo de la sentencia parece, por lo tanto, que el TJUE haya dado un paso atrás ${ }^{21}$, «como en un baile de pareja, un tango (un baile que el TJUE llama "diálogo de juez a juez")» (Bin 2018: 1), el TJUE ha insinuado un elegante paso atrás para que la propia pareja pudiera avanzar sin perder el abrazo (Bin, 2018: 1) ${ }^{22}$. De tal forma, la STJUE en el asunto M.A.S. y M.B. ha frenado el temido enfrentamiento con la Corte costituzionale.

21 Según Manes (2018: 1), en la sentencia Taricco II «the Grand Chamber has stepped back from the 'judicial adventurism' of the previous Taricco judgment [...] The political rationale underpinning Taricco II seems likewise clear: it seems that the Grand Chamber felt that it was at a confusing crossroads, or even in a "one-shot game". In particular, had the Court safeguarded the need to guarantee the effectiveness of EU law and "primauté cou^te que cou^te", it would have accepted the risk of jeopardizing, if not ruining, the remarkable achievements of EU harmonization in criminal matters. Therefore, the Court opted for a strategic retreat to avoid a bitter conflict. Not mors tua vita mea, rather vita tua, vita mea. This 'first lesson' confirms the notoriously pragmatic approach of the Court of Justice».

22 Al respecto, Bin (2018: 3) afirma, "Come in un ballo di coppia (un ballo che la Corte di giustizia chiama "dialogo da giudice a giudice"), la Corte ha accennato un elegante passo indietro per far avanzare la propria partner senza perdere l'abbraccio; ma, allo stesso tempo, ha posto un punto fermo, un perno attorno al quale la invita a ruotare 
Esta última, en la decisión núm. 115/2018, del 31 de mayo de 2018, atendiendo a lo afirmado en M.A.S. y M.B., ha dictado una sentencia desestimatoria (sentenza di rigetto), en la que declara infundadas las cuestiones de legitimidad constitucional sobre el art. 2 de la Ley 130/2008, en relación con la ejecución del art. 325 del TFUE, tal y como ha sido interpretado por el TJUE en la sentencia Taricco I, aunque cierra el ingreso de la «regla Taricco» en el ordenamiento italiano. Dicha regla, por lo tanto, sería inaplicable por contraria a la determinación de la norma penal, que es a la vez un principio supremo del orden constitucional italiano y un principio cardinal del derecho de la UE (art. 49 de la Carta) ${ }^{23}$.

Tras este breve recorrido por las principales etapas de la «saga Taricco», ante todo es oportuno preguntarse si la sentencia M.A.S. y M.B. ha puesto efectivamente fin a este asunto y si en la ponderación realizada entre garantía del mayor estándar de tutela de los derechos fundamentales (en el caso de que se trata principio de legalidad penal y sus corolarios) versus intereses financieros de la UE, el TJUE ha dado efectivamente prevalencia a los primeros. Es decir, ¿la sentencia M.A.S. y M.B., en la que el TJUE ha tendido «una ramita de olivo» (en italiano: «un ramoscello di ulivo», Ruggeri: 2017b) a la Consulta, ha conseguido llegar a un punto de encuentro entre la perspectiva europea y aquella nacional del principio de legalidad en materia penal? ¿O estamos simplemente ante una situación de tregua después de la tormenta, que no ha resuelto los principales nudos del caso Taricco sobre todo desde el punto de vista de su aplicación en el ámbito del ordenamiento italiano?

Y por último, en relación con la posición de la Corte costituzionale en este asunto cabe reflexionar sobre si refleja la dialéctica que caracteriza las

per invertire la propria direzione». En cambio, Longo (2018: 4), habla más bien de un «diálogo sin comunicación» o un «diálogo aparente», considerando que «la Corte di Giustizia, che doveva necessariamente fare i conti da un lato con quanto sviluppato nella motivazione della sentenza Taricco I e, dall'altro, con gli interrogativi sollevati dal giudice del rinvio, sviluppa un ragionamento che si muove lungo tre direttrici, senza che ci sia un reale confronto con quanto affermato dalla Corte costituzionale». $\mathrm{Al}$ respecto, la Corte Costituzionale afirma que: «L'inapplicabilità della "regola Taricco", secondo quanto riconosciuto dalla sentenza M.A. S., ha la propria fonte non solo nella Costituzione repubblicana, ma nello stesso diritto dell'Unione, sicché ha trovato conferma l'ipotesi tracciata da questa Corte con l'ordinanza n. 24 del 2017, ovvero che non vi sia alcuna ragione di contrasto. Ciò comporta la non fondatezza di tutte le questioni sollevate, perché, a prescindere dagli ulteriori profili di illegittimità costituzionale dedotti, la violazione del principio di determinatezza in materia penale sbarra la strada senza eccezioni all'ingresso della "regola Taricco" nel nostro ordinamento". 
relaciones entre tribunales constitucionales nacionales y TJUE o si más bien es la expresión de la involución generalizada que está atravesando el proceso de integración europea, en el que se está asistiendo a un retorno al nacionalismo y a la defensa cerrada de supuestas identidades nacionales.

Que la sentencia M.A.S. y M.B. deje más de una cuestión abierta se puede deducir ante todo de que el TJUE no se haya detenido intencionadamente en algunos de los perfiles más controvertidos que esta «saga» plantea. Muchos son, por lo tanto, los interrogantes irresueltos y las incertidumbres que dicho asunto plantea.

\section{LA IMPLÍCITA APLICACIÓN DE LOS CONTRALÍMITES POR PARTE DEL TJUE}

En la «saga Taricco» el tan invocado conflicto entre el pluralismo inherente a la dimensión multilevel y los rasgos específicos de los ordenamientos internos de los Estados miembros (como la naturaleza sustantiva de la prescripción en Italia), los cuales son expresión de la identidad nacional, esconde en realidad dos elementos que constituyen la clave de lectura de las principales problemáticas de este asunto.

Por un lado, la relevancia de la sentencia Taricco $I$ ha sido sobrestimada. La doctrina italiana la consideró como la ocasión óptima para instar a la Corte costituzionale a elevar su voz autorizada y aplicar finalmente los contralímites (esto no quita las muchas críticas que se pueden avanzar contra esta sentencia y los reales problemas de aplicabilidad que esta presenta).

Y por otro, este asunto demuestra los fallos no solo de la normativa italiana en materia de prescripción que ha sido reiteradamente tachada de incompatible con el derecho de la Unión, sino también los problemas estructurales de la maquinaria judicial de este país que no consigue garantizar el derecho a un proceso sin dilaciones indebidas.

Dicho esto y considerando, por lo tanto, que el problema de fondo no consiste tanto - en la opinión de quien escribe- en que la doctrina Taricco fuera contraria a la naturaleza sustantiva de la prescripción en Italia, tal y como ha sido interpretada por jurisprudencia constante de la Corte costituzionale ${ }^{24}$, sorprende bastante que el TJUE en la sentencia Taricco II haya omitido cualquier referencia a la doctrina de los contralímites (Bin, 2018: 1;

24 Al respecto, véanse las siguientes sentencias de la Corte Costituzionale: 275/1990, dep. 31.05.1990; 324/2008, dep. 1.08.2008 y 394/2006, dep. 23.11.2006; ord. n. 65/2008, dep. 14.03.2008. 
Chessa, 2018: 3 ss.), de la que, en cambio, la Corte costituzionale en el auto 24/2017 había sido intérprete.

En aquella sede, de hecho, la Consulta, haciendo más veces referencia a la ineludible contraposición entre primacía del derecho de la UE e identidad nacional, había puesto de relieve que «la primacía del derecho de la Unión no expresa una mera articulación técnica del sistema de las fuentes nacionales y supranacionales ${ }^{25}$, sino que refleja más bien la tensión hacia la unidad en un ordenamiento plural (art. 2 TUE), que pretende asegurar la paz y la justicia entre las naciones. Tales objetivos justifican una renuncia a espacios de soberanía, incluso si son definidos por normas constitucionales (art. 11 Const. it.) ${ }^{26}$. Esta tensión es posible en virtud de la existencia de un índice de diversidad mínimo, que es necesario para preservar la identidad nacional ínsita en la estructura fundamental del Estado miembro (art. 4, párr. 2, del TUE). En caso contrario, el derecho de la Unión y las sentencias del TJUE, imponiendo a los Estados miembros la renuncia a sus principios fundamentales, llegarían a disolver el fundamento constitucional del que han tenido origen por voluntad de los Estados miembros.

$\mathrm{Al}$ margen de todo ello, a pesar de que la sentencia M.A.S. y M.B. no diga nada al respecto, los contralímites están presentes e, incluso, se puede afirmar que este pronunciamiento ofrece la confirmación de su cumplida «europeización» (Ruggeri, 2017a: 5 y ss.) ${ }^{27}$. El TJUE habría realizado el control del respeto de la identidad nacional (Identitätskontrolle), utilizando, aunque tácitamente, el contralímite del principio de legalidad en materia penal, del que ha ofrecido una lectura sistemática en clave europea, para regular la primacía del derecho de la UE y adaptarlo a las especificidades del ordenamiento jurídico italiano (que considera la prescripción de los delitos como un instituto de derecho penal sustantivo). En este supuesto concreto, las identidades nacionales habrían permitido «regular la aplicación del Derecho de la UE» (Balaguer Callejón, 2017) a fin de evitar el «conflicto» abierto ${ }^{28}$. Es evidente

25 Corte cost., ord. n. 24/2017, cons. in diritto n. 6.

26 Ibid.

27 Véase Ruggeri (2016: 2), según el cual los contralímites serían aquellos principios que «esprimono l'identità costituzionale assiologicamente intesa, al cui servizio la sovranità si dispone, in essa rivendicando la sua ragione d'essere, la sua giustificazione e il fine. Il limite di tali principi (contro-limiti) concretamente non è stato fatto valere. Al pari dell'araba fenicia della tradizione si sa che esso c'è e che deve esserci ma non si sa dove sia».

28 Según Balaguer Callejón (2017), la tutela jurisdiccional de la identidad constitucional se desarrolla, tanto en términos de convergencia como en términos de conflicto. Las relaciones de convergencia entre los dos espacios constitucionales, entre el derecho 
que el TJUE, introduciendo una excepción a la primacía del derecho de la UE, ha sido obligado a aceptar implícitamente el contralímite opuesto por la Corte costituzionale, antes de que esta lo declarara abiertamente ${ }^{29}$.

El Tribunal de Justicia pondera los distintos intereses en juego con prudencia y cautela, no desmintiendo en ningún momento la sentencia/jurisprudencia Taricco I. Ante todo reafirma la importancia del reenvío prejudicial como instrumento de "cooperación» funcional a instaurar el «diálogo de juez a juez» y a asegurar la unidad de interpretación del derecho de la Unión y la coherencia, la eficacia plena y la autonomía de este derecho ${ }^{30}$.

La solución del TJUE se basa en la interpretación sistemática y teleológica, funcional a la estructura y a los objetivos de la UE, de la cláusula contenida en el art. 4.2 $\mathrm{TUE}^{31}$ sobre el respeto de las identidades constitucionales nacionales, la cual constituye el punto de conexión entre el ordenamiento UE y el ordenamiento de los Estados miembros, con otros principios igualmente fundamentales del derecho constitucional europeo, in primis el principio de la primacía y de la eficacia directa, los valores comunes sobre los que se asienta

europeo y el derecho interno, se traducen, por un lado, en el nivel propiamente europeo en el uso por parte del TJUE de las particularidades constitucionales internas de los Estados miembros (definidas ahora como «identidades constitucionales») para regular la aplicación del principio de la primacía, cuya base reside en el art. 4.2 TUE. En el asunto Omega, por ejemplo, el Tribunal de Justicia hace referencia a la dignidad humana como principio estructural de la identidad constitucional de Alemania, que legitima la restricción del principio fundamental del derecho de la UE de la libre circulación de las mercancías, de las prestaciones y de los servicios [Sentencia del Tribunal de Justicia (en adelante TJ) de 14 de octubre de 2004, Omega, C-36/02, EU:C:2004:614]. Y por otro, en el nivel nacional, se trata de integrar el derecho europeo en el parámetro de constitucionalidad interno y de considerar el derecho constitucional interno en el juicio de legitimidad ejercido por el TJUE. La dimensión conflictual encuentra en cambio su expresión en el concepto de contra-límite al derecho de la UE.

29 En este sentido, véase Amalfitano (2017).

30 Dictamen del TJUE de 18 de diciembre de 2014, Adhesión de la UE al CEDH, 2/13, EU:C:2014:2454, apdo. 176.

31 El art. 4.2 TUE, que contiene la cláusula sobre el respeto de las identidades constitucionales nacionales, prevé que: «La Unión respetará la igualdad de los Estados miembros ante los Tratados, así como su identidad nacional, inherente a las estructuras fundamentales políticas y constitucionales de éstos, también en lo referente a la autonomía local y regional. Respetará las funciones esenciales del Estado, especialmente las que tienen por objeto garantizar su integridad territorial, mantener el orden público y salvaguardar la seguridad nacional. En particular, la seguridad nacional seguirá siendo responsabilidad exclusiva de cada Estado miembro». 
este sistema interordinamental caracterizado por el pluralismo (art. 2 TUE), el valor jurídicamente vinculante de la Carta, igual a aquel de los tratados en el ámbito de aplicación del derecho de la Unión (art. 6.1 TUE y art. 51 de la Carta), el carácter complementario de las tradiciones constitucionales comunes a los Estados miembros, que incorporan los derechos fundamentales bajo la forma de principios generales del derecho de la Unión (art. 6.3 TUE), y el principio de cooperación leal (art. 4.3 TUE) y de confianza mutua (art. 82 TFUE), que constituye la base, el pilar, del espacio europeo de libertad, seguridad y justicia ${ }^{32}$.

De tal forma, matizando la doctrina Taricco I, el TJUE habría demostrado que identidades nacionales y primacía del derecho de la UE no son dos conceptos necesariamente antitéticos, destinados a una insanable contradicción. En este sentido, la primacía debería concurrir a reforzar la identidad constitucional, "permitiendo llegar a síntesis axiológicamente apreciables de valores constitucionales» al fin de garantizar la unidad del «sistema» (Ruggeri, 2016: 15). La solución de las tensiones que pueden surgir entre estas dos categorías se remite al caso concreto, que requerirá la realización de una determinada ponderación de los intereses en juego.

$\mathrm{Si}$, por lo tanto, el éxito de la respuesta del TJUE, en general, depende de las particularidades del asunto de que se trata, en principio la sentencia Taricco II no establecería una excepción también a la doctrina Melloni ${ }^{33}$. En esta línea, ya la Corte costituzionale en el auto 24/2017 había observado que Taricco no es Melloni ${ }^{34}$. De hecho, en este último asunto el TJUE afirmó que la Decisión Marco 2009/299/JAI del Consejo, de 26 de febrero de 2009 ${ }^{35}$, mediante la

32 Según Fichera (2018: 10), "Quella che emerge, in altre parole, è una visione non gerarchica ma eterarchica o "perspettivista", in cui la Corte del Lussemburgo, pur mantenendo il punto di vista dell'ordinamento europeo, allo stesso tempo è disposta a riconoscere la validità della presa di posizione della Consulta, dal punto di vista dell'ordinamento italiano. Tale impostazione, si badi bene, non esclude il conflitto, ma ne circoscrive la possibilità di realizzazione nel momento stesso in cui utilizza la nozione di "tradizioni costituzionali comuni" — nell'intento di dimostrare come la normativa sui diritti umani e principi fondamentali, sia a livello nazionale che a livello sovranazionale,è inquadrabile in una visione sistematica e teleologica».

33 Sentencia del Tribunal de Justicia de 26 de febrero de 2013, Melloni, C-399/11, EU:C:2013:107. Sobre el asunto Melloni, se reenvía ex multis a: Besselink (2014: 531-552); Faggiani (2014: 1-28); Manacorda (2013: 4-11); Martín Rodríguez (2013: 1-45); Ruggeri (2013: 399-408); Sarmiento Ramírez Escudero (2013: 1267-1304); Torres Pérez (2014: 308-331).

34 Corte Cost., ord. n. 24/2017, cons. in dir. n. 8.

35 DOUE L 81, de 27 de marzo de 2009, pp. 24-36. 
que se armonizan las condiciones de ejecución de la orden europea de detención en caso de condena in absentia, "refleja el consenso alcanzado por los Estados miembros en su conjunto con respecto al alcance, según el derecho de la Unión, de los derechos procesales» de las personas que se encuentran en tales circunstancias.

Si se hubiera permitido a un Estado miembro aplicar el art. 53 de la Carta para subordinar la entrega de una persona condenada en rebeldía a la condición, no prevista por la Decisión Marco 2009/299/JAI, de que la sentencia de condena pueda ser objeto de revisión en el Estado miembro de emisión, al fin de evitar una lesión del derecho a un proceso equitativo y de los derechos de la defensa garantizados por la Constitución del Estado miembro de ejecución, se hubiera puesto en discusión la uniformidad del estándar de tutela de los derechos fundamentales definido por la mencionada decisión marco, y se hubieran vulnerado los principios de confianza y reconocimiento mutuo que ésta pretende reforzar, perjudicando la efectividad de dicha decisión marco.

Por consiguiente, en aquella circunstancia se consideró oportuno aplicar el estándar de tutela garantizado en sede europea aunque inferior a aquel previsto por la Constitución española. Y precisamente esta sería la demostración de que primacía e identidad pueden realizarse (y efectivamente se realizan) juntas, por lo menos cuando se consiga utilizar los mecanismos procesales adecuados (in primis el reenvío prejudicial, que constituye el motor del diálogo judicial europeo) y las ponderaciones realizadas por los distintos órganos jurisdiccionales (Ruggeri, 2017a: 16).

La tendencia del TJUE a elevar el estándar de tutela en función de las circunstancias del caso concreto y en todo caso en el respeto al ámbito de aplicación del derecho de la UE y a sus principios fundamentales se encuentra también en la sentencia relativa a los asuntos acumulados Aranyosi y Căldăra$r u^{36}$, en la que, por primera vez, se han intentado definir los «límites constitucionales de la confianza mutua» (Martín Rodríguez, 2016) ${ }^{37}$ en relación con la aplicación de una eurorden.

En este asunto el Tribunal de Luxemburgo tuvo que evaluar si en el caso de que las condiciones de reclusión sean degradantes como resultado de una

36 Sentencia del TJUE (Gran Sala) de 5 de abril de 2016, Aranyosi y Căldăraru, C-404/15 y C-659/15 PPU, EU:C:2016:198.

37 Según Martín Rodríguez (2016: 882), en la sentencia Aranyosi, el TJUE, aun sin mencionarla de forma explícita, asume como punto de partida «el espíritu de la jurisprudencia $N$. S.-Abdullahi, consiguiendo articular una "excepción mejor definida sustantiva y, sobre todo, procedimentalmente" ", a través del denominado "doble test o control general y concreto». Sobre la confianza mutua en Aranyosi se reenvía también a: Anagnostaras (2016: 1675-1704). 
deficiencia sistémica de los centros penitenciarios del Estado miembro emisor (Hungría y Rumanía), las autoridades judiciales de ejecución (Alemania) pueden negarse a entregar al encausado; y si, en el supuesto de que se quebrara la confianza recíproca entre los Estados miembros por la violación de los derechos fundamentales que estos tienen que respetar, sería posible limitar el principio de reconocimiento mutuo.

Aunque es cierto que esta sentencia reafirma que el principio de reconocimiento mutuo, que constituye el pilar para la construcción de un ELSJ sin fronteras interiores basado en la cooperación judicial penal, descansa en la confianza recíproca entre los Estados miembros en que sus respectivos ordenamientos jurídicos nacionales están en condiciones de proporcionar una protección equivalente y efectiva de los derechos fundamentales, reconocidos en el ámbito de la Unión, en particular en la Carta, se admite que la presunción de respeto de los derechos fundamentales y, por tanto, la obligación de ejecución de una euroorden no son absolutas, pudiendo romperse en circunstancias excepcionales ${ }^{38}$.

Por esto, además de los supuestos tasados de no ejecución obligatoria (art. 3 de la Decisión Marco), de no ejecución facultativa (art. 4 y 4 bis de la Decisión Marco), de los previstos en el art. 5, como en el caso del proceso in absentia, en los que la ejecución puede ser subordinada a la prestación de determinadas garantías por parte del Estado de emisión, y de suspensión en caso de violación grave y persistente por parte de uno de los Estados miembros de los principios contemplados en el art. 2 TUE (art. 7 TUE), la obligación de ejecutar una euroorden dejaría de existir en aquellas situaciones en que la aplicación del derecho de la UE (en este caso de la decisión marco sobre la euroorden) podría vulnerar derechos o valores equivalentes o superiores por parte del mismo derecho de la Unión.

Por consiguiente, y aquí parece que el TJUE estuviera respondiendo a la sentencia del BvG en el recurso contra el Sr. R., de 15 de diciembre de 201539, la prohibición de las penas o los tratos inhumanos o degradantes, establecida en el art. 4 de la Carta, tendría carácter absoluto, ya que es indisociable del respeto de la dignidad humana (art. 1 de la Carta). El carácter absoluto de dicha prohibición está confirmado por el art. 3 del CEDH (ex art. 52.3 de la Carta) y por el art. 15.2 del CEDH, que no autoriza ninguna derogación. Tales artículos (arts. 1 y 4 de la Carta y 3 del CEDH) consagrarían uno de los

38 Dictamen 2/13, cit., apdo. 191.

39 BVerfG, 15.12.2015 - 2 BvR 2735/14. Sobre este pronunciamiento véanse los siguientes comentarios: Arzoz Santisteban (2016: 109-141) y Nowag (2016: 1441 1453). 
valores fundamentales de la Unión y de sus Estados miembros, en virtud de su vinculación con la dignidad humana ${ }^{40}$.

Sin embargo, la importancia de la sentencia Aranyosi y Căldăraru va más allá, sentando un precedente para la progresiva inclusión de otras excepciones al principio de reconocimiento mutuo en materia penal. En definitiva, aunque la confianza mutua en materia penal supondría un reconocimiento automático de las decisiones emitidas por parte del Estado de emisión, el TJUE, consciente de los problemas estructurales y sistemáticos que caracterizan a algunos Estados de la UE, prefiere establecer un filtro ulterior. No se trata de un fracaso del reconocimiento mutuo, puesto que dicha «excepción» se aplicaría en casos individualizados y estaría sometida a un procedimiento de control, sino de la necesidad de que algunos Estados adopten medidas para alcanzar el estándar mínimo de protección establecido a nivel europeo y garantizar un mejor funcionamiento de este mecanismo (Faggiani, 2017a: 167).

De todas formas, del análisis de la trilogía Taricco I y II, Melloni y Aranyosi se puede deducir que la cooperación judicial en materia penal, que constituye un ámbito totalmente determinado/armonizado por el derecho de la UE, se ha convertido en una de las prioridades no solo del TJUE, sino de la UE en su conjunto, puesto que de los mecanismos de aproximación de las legislaciones nacionales, sustantivas y procesales, y de la coordinación (horizontal y vertical) entre los jueces europeos depende la construcción de un sistema de justicia común y, por lo tanto, el proceso de integración europea.

Una confirmación en este sentido se encuentra también en la reciente adopción en octubre de 2017 del Reglamento (UE) 2017/1939 del Consejo por el que se establece una cooperación reforzada (el primer caso de cooperación reforzada en materia penal) para la creación de la Fiscalía Europea, que constituye sin duda un hito en este proceso $^{41}$. La Fiscalía Europea, que atendiendo a lo dispuesto en el art. 86 TFUE debe instituirse a partir de Eurojust, tendrá la función de «investigar, procesar y llevar a juicio a los autores de los delitos contra los intereses financieros de la Unión con arreglo a la Directiva (UE) 2017/1371 del Parlamento Europeo y del Consejo, de 5 de julio de 2017, sobre la lucha contra el fraude que afecta a los intereses

40 Sentencia Aranyosi y Căldăraru, cit., apdos. 85-87.

41 DOUE L 283/1, 31.10.2017. El 3 de abril de 2017, ante la falta de unanimidad en el Consejo en relación con la propuesta de reglamento relativo a la creación de la Fiscalía Europea, en el seno de la UE se activó el procedimiento de cooperación reforzada, que alcanzó, el 8 de junio de 2017, el apoyo de veinte Estados miembros. Los demás Estados miembros podrán adherirse en cualquier momento, una vez adoptado el reglamento. 
financieros de la Unión a través del Derecho penal ${ }^{42}$, así como los delitos que están indisociablemente vinculados con ellos». Tales competencias podrán ser ampliadas a otros delitos graves de dimensión transfronteriza previa decisión unánime del Consejo Europeo.

\section{III. ¿̇LA NATURALEZA PROCESAL DE LA PRESCRIPCIÓN TRAS LA DIRECTIVA PIF?}

El segundo perfil que no ha sido resuelto por la sentencia Taricco II es el de la naturaleza de la prescripción de los delitos. De lo que el TJUE no dice expresamente en este pronunciamiento parece que la Directiva (UE) 2017/1371 haya reconfigurado este instituto, otorgándole valor procesal.

Un planteamiento parecido, sin embargo, se alejaría de la sentencia $T a$ ricco I, en la que se había limitado a excluir la aplicación del art. 49 de la Carta a la prescripción de los delitos (y por lo tanto también del art. $7 \mathrm{CEDH}$ en virtud de la "cláusula de equivalencia» ex art. 52.3 CEDH $)^{43}$, considerando que no viola el principio de legalidad en materia penal y dando a entender que los Estados están libres de atribuir a este instituto naturaleza sustantiva o procesal de conformidad con su regulación constitucional ${ }^{44}$.

42 DOUE L 198, 28.7.2017, pp. 29-41.

43 Sentencia Taricco, cit., apdos. 55-57. En dicho pronunciamiento, el TJUE reenvía a la jurisprudencia del TEDH sobre el art. $7 \mathrm{CEDH}$, relativo al principio de legalidad en materia penal, que a partir de la sentencia Cö̈me y otros c. Bélgica, 32492/96, $32547 / 96,32548 / 96,33209 / 96$ y 33210/96, párr. 149, ha afirmado que el instituto de la prescripción, independientemente de la naturaleza sustantiva o procesal, que los distintos ordenamientos le pueden atribuir no está amparado por dicho precepto. Según el TJUE, «en efecto, con arreglo a esa jurisprudencia, la prórroga del plazo de prescripción y su aplicación inmediata no constituyen una vulneración de los derechos garantizados por el artículo 7 del referido Convenio, puesto que no puede considerarse que esta disposición impida la ampliación de los plazos de prescripción cuando los hechos imputados no han prescrito» (apdo. 56). Por lo tanto, aunque una aplicación in malam partem de tales términos podría producir efectos desfavorables en la esfera jurídica del imputado, afectando sobre todo a la certeza del derecho, no violaría el principio de legalidad en materia penal.

44 En la sentencia M.A.S. y M.B., cit., apdos. 43-45, el TJUE afirma que «dicho esto, procede añadir que el ámbito de la protección de los intereses financieros de la Unión mediante la imposición de sanciones penales constituye una competencia compartida entre la Unión y los Estados miembros, en el sentido del artículo 4 TFUE, apartado 2. En el presente asunto, en el momento de los hechos controvertidos en el proce- 
Estos, por lo tanto, no tendrían que renunciar a aplicar las propias disposiciones y tradiciones constitucionales, cuando aseguren al reo un mayor nivel de tutela. Se trata, en efecto, de un aspecto que no afecta directamente a las competencias de la UE, ni a las normas de la Unión, ni impone alguna exigencia de uniformidad en el ámbito jurídico europeo ${ }^{45}$.

$\mathrm{Al}$ margen de todo ello, el TJUE en la sentencia M.A.S. y M.B. reitera básicamente la doctrina Taricco $I$, aunque precisa sus contenidos, justificando la necesidad de aclarar algunos perfiles que no había tenido ocasión de abordar en aquella circunstancia, porque no le habían sido planteados en el reenvío prejudicial ${ }^{46}$. Ante todo, reafirma que la normativa italiana en materia de prescripción es incompatible con el derecho de la UE, porque viola las obligaciones derivadas del art. 325 TFUE, párr. 1, que tiene efectos directos, e invita al legislador italiano a intervenir, reformando la normativa en este ámbito.

La República Italiana, en este sentido, no ha adoptado sanciones penales dotadas de carácter efectivo y disuasorio que eviten la impunidad y consigan reprimir casos de fraude grave que perjudican los intereses financieros de la UE en materia IVA, no permitiendo garantizar eficazmente el cobro de dicho impuesto; ni ha adoptado para luchar contra el fraude que viola los intereses financieros de la Unión, en particular en materia de IVA, las mismas medidas

dimiento principal, el régimen de prescripción aplicable a las infracciones penales relativas al IVA no había sido objeto de armonización por el legislador de la Unión, que únicamente se produjo después, de forma parcial, mediante la adopción de la Directiva (UE) 2017/1371, del Parlamento Europeo y del Consejo, de 5 de julio de 2017, sobre la lucha contra el fraude que afecta a los intereses financieros de la Unión a través del Derecho penal (DO 2017, L 198, p. 29). Por tanto, la República Italiana tenía libertad, en aquel momento, para prever que, en su ordenamiento jurídico, ese régimen estuviese comprendido, al igual que las normas relativas a la definición de las infracciones y la determinación de las penas, en el Derecho penal material y quedara sometido, como estas últimas normas, al principio de legalidad de los delitos y las penas».

Corte costituzionale, ord. n. 24/2017, cons. in dir. n. 4

46 Nisticò (2018: 3) considera que la «narrativa» que el TJUE acredita en la Taricco II pretende «preparar el terreno para dar un paso atrás respecto a las conclusiones a las que había llegado en la Taricco I». Según el A., "e vale la pena di evidenziare che tale prospettazione è sostenuta persino al prezzo di avvalorare ricostruzioni francamente inverosimili; è infatti a mio avviso ovvio che ad un giudice tecnicamente preparato come la Corte di Lussemburgo non poteva certamente sfuggire, già nel 2015 e quand'anche nessuno la avesse evocata in giudizio, una questione tanto scottante come quella dei rapporti complessi (per usare un eufemismo) tra disapplicazione in malam partem e legalità penale». 
que para luchar contra el fraude que viola los intereses financieros. Solo una intervención, en tal sentido, del legislador y una mayor rapidez por parte de los jueces para resolver los procesos podrían contribuir a afrontar un problema que en el ordenamiento italiano ha adquirido dimensiones estructurales. Sin embargo, como es sabido, la reforma de la prescripción en Italia es una asignatura pendiente desde hace tiempo. Ni la ex legge Cirielli ni la más reciente «reforma Orlando ${ }^{47}$ han resuelto los nudos que este instituto presenta.

A todo ello hay que añadir los problemas concernientes a las dilaciones indebidas de los procesos penales, que han sido reprochadas a este Estado en reiteradas ocasiones también por el $\mathrm{TEDH}^{48}$. En este sentido, el TJUE no se debería haber limitado a "matizar» la doctrina Taricco I (lo cual ha sido sin duda muy positivo, contribuyendo de tal forma a reforzar su papel de garante de los derechos fundamentales en el ámbito de aplicación del Derecho de la UE), sino que debería también haber invitado a la Comisión Europea a activar el procedimiento de infracción (Bin, 2017: 9; Guazzarotti, 2017). A este propósito, no hemos de olvidar que la sentencia Taricco II, a través de una

47 Véase la Legge 5 dicembre 2005, n. 251, «Modifiche al codice penale e alla legge 26 luglio 1975 , n. 354, in materia di attenuanti generiche, di recidiva, di giudizio di comparazione delle circostanze di reato per i recidivi, di usura e di prescrizione», Gazzetta Ufficiale n. 285 del 7 dicembre 2005 y Legge 23 giugno 2017, n. 103, «Modifiche al codice penale, al codice di procedura penale e all'ordinamento penitenziario, GU n. 154, 4.07.2017.

La excesiva duración del proceso penal por la ineficiencia de la maquina judicial es un problema sistémico del ordenamiento italiano, que ha sido puesto de relieve también por el TEDH, que ha condenado a este Estado en reiteradas ocasiones por la violación del art. 6.1 CEDH. Entre los varios pronunciamientos del TEDH al respecto, véase Simaldone vs. Italy, no. 22644/03, árr. 36, ECHR, 31 de marzo de 2009.

Si el ordenamiento no consigue garantizar que el proceso penal se cierre en un plazo razonable, tampoco la pena puede desarrollar una función general preventiva, puesto que con el transcurso del tiempo se atenúan las razones que justifican la imposición de la pena y aumentan las dificultades de reconstrucción probatoria del hecho, haciendo aún más complicado para el imputado involucrado en el procedimiento penal ejercer el derecho a la defensa. Por otra parte, las circunstancias subjetivas del presunto culpable pueden variar, resultando la sanción penal desproporcionada respecto a los supuestos delictivos cometidos y, por lo tanto, inidónea a la reeducación y resocialización del reo (perspectiva especial preventiva). Desde este punto de vista, el instituto de la prescripción del delito constituye para el presunto culpable una garantía contra la duración irrazonable del proceso y la pretensión punitiva del Estado, impidiendo que el proceso pueda prolongarse indefinidamente. El legislador tiene el deber de garantizar la duración razonable del proceso, que encuentra su fundamento no solo en el art. 111.2 Const. it., sino también en el art. 117.1 Const. it., en relación con el art. 6.1 CEDH, según la interpretación «garantista» del TEDH. 
«especie de inaplicación de la inaplicación», cuando la Taricco I sea susceptible de vulnerar el principio de legalidad en materia penal, ha conseguido resolver momentáneamente la disputa entre Corte costituzionale/TJUE pero no ha podido eliminar todos los problemas que este asunto plantea especialmente en el ámbito del ordenamiento italiano.

A continuación, tras reconfirmar la sentencia Taricco I, el TJUE empieza a afrontar el problema de la naturaleza de la prescripción de los delitos en materia IVA, partiendo de la premisa de que la tutela de los intereses financieros de la Unión a través de la previsión de sanciones penales constituye una competencia concurrente de la Unión y de los Estados miembros.

En el momento de los hechos objeto del procedimiento principal, el régimen de prescripción aplicable a las infracciones penales relativas al IVA no había sido objeto de armonización por el legislador de la Unión, que únicamente se produjo después, de forma parcial ${ }^{49}$, mediante la adopción de la Directiva (UE) 2017/1371 del Parlamento Europeo y del Consejo, de 5 de julio de 2017, sobre la lucha contra el fraude que afecta a los intereses financieros de la Unión a través del derecho penal ${ }^{50}$.

49 Sentencia M.A.S. y M.B., cit., apartado 44.

50 La Directiva PIF en el artículo 12 establece una armonización mínima en el ámbito de la prescripción de las infracciones penales que afectan a los intereses financieros de la Unión, disponiendo que: «1. Los Estados miembros adoptarán las medidas necesarias para establecer un plazo de prescripción que posibilite la investigación, el enjuiciamiento, el juicio oral y la resolución judicial de las infracciones penales a que se refieren los artículos 3, 4 y 5 durante un período suficiente a partir de la comisión de esas infracciones, de modo que estos se puedan perseguir de manera eficaz. 2. Los Estados miembros adoptarán las medidas necesarias para que las infracciones penales a que se refieren los artículos 3, 4 y 5 que sean punibles con una pena máxima de al menos cuatro años de prisión se sometan a investigación, enjuiciamiento, juicio oral y resolución judicial de las infracciones penales en un plazo de al menos cinco años a partir del momento en que se cometió la infracción. 3. No obstante lo dispuesto en el apartado 2, los Estados miembros podrán fijar un plazo de prescripción inferior a cinco años pero no inferior a tres años, siempre y cuando garanticen que ese período pueda ser interrumpido o suspendido por determinados actos. 4. Los Estados miembros tomarán todas las medidas necesarias para permitir la ejecución de: a) una pena de más de un año de prisión, o alternativamente; b) una pena de prisión en el caso de una infracción penal que sea punible con una pena máxima de al menos cuatro años de prisión, impuesta a raíz de una sentencia condenatoria firme por una infracción penal contemplada en los artículos 3, 4 o 5, durante un período de al menos cinco años a partir de la fecha de la condena firme. Este período puede incluir prórrogas del período de prescripción que se deriven de su interrupción o suspensión». 
Por lo tanto, antes de la directiva PIF, la República Italiana estaba legitimada a configurar la prescripción de las infracciones como un instituto de derecho material, sometido al principio de legalidad de los delitos y de las penas $^{51}$, puesto que no se trataba de un ámbito totalmente determinado por el derecho de la UE (art. 51 de la Carta) y las autoridades y los jueces nacionales podían aplicar los estándares nacionales de tutela de los derechos fundamentales, entre ellos los derechos de los imputados derivados del principio de legalidad de los delitos y de las penas, siempre y cuando — conforme a la doctrina Fransson ${ }^{52}$ - esta aplicación no comprometiera el nivel de protección previsto por la Carta, según su interpretación por el Tribunal de Justicia, ni a la primacía, la unidad y la efectividad del derecho de la Unión.

En cambio, a partir de la directiva PIF, que ha armonizado este sector, la heterogeneidad existente hasta aquel momento en el ámbito de la UE ya no tendría sentido. La excepción a la regla Taricco I estaría legitimada, por lo tanto, por el hecho de que en este caso la aplicación del mayor nivel de protección garantizado por el ordenamiento de los Estados miembros no perjudicaría la primacía, la unidad y la efectividad del derecho de la UE.

De este planteamiento se deduce también que la sentencia Taricco I no puede ser aplicada a las situaciones anteriores, es decir a aquellas en las que la prescripción ya había madurado antes de la decisión del TJUE, del 8 de septiembre de 2015, porque sería contraria a las indicaciones de la jurisprudencia de la Unión ${ }^{53}$ y violaría los principios fundamentales del sistema penal italiano; $y$ tampoco a las situaciones surgidas antes de la mencionada sentencia y a la espera de una sentencia definitiva, respecto de las que la persona imputada no habría podido prever razonablemente la intervención del TJUE.

51 Sentencia M.A.S. y M.B., cit., apartado 45.

52 TJUE, Sentencia de 26 de febrero de 2013, Åkerberg Fransson, C 617/10, EU: C: 2013:105, apdo. 29 y jurisprudencia citada.

53 Sentencia M.A.S. y M.B., cit., apdo. 60. Al respecto, se afirma: «Por otra parte, los requisitos mencionados en el apartado 58 de la presente sentencia suponen un obstáculo a que, en los procedimientos que afectan a personas acusadas de haber cometido infracciones en materia del IVA antes de que se pronunciase la sentencia Taricco, el juez nacional no aplique las disposiciones del Código Penal controvertidas. En efecto, el Tribunal de Justicia ya ha destacado, en el apartado 53 de la mencionada sentencia, que, debido a la inaplicación de esas disposiciones, podrían imponerse a esas personas sanciones que, con toda probabilidad, habrían evitado si se hubieran aplicado las mencionadas disposiciones. Así, esas personas podrían quedar sujetas retroactivamente a condiciones de exigencia de responsabilidad penal más severas que las vigentes en el momento de la comisión de la infracción». 
Los interesados, como subraya también la Corte costituzionale en el auto 24/2017, no podían prever razonablemente, antes de la sentencia Taricco I, que el art. 325 TFUE habría impuesto al juez nacional, atendiendo a las condiciones establecidas en dicha sentencia, no aplicar dichas disposiciones. La no aplicación no puede comportar la violación de los derechos fundamentales.

Sin embargo, el aspecto más crítico de este planteamiento consiste en que la irretroactividad de la primera sentencia Taricco no había sido prevista por ley, sino que había sido establecida por el TJUE, cuyo papel por lo tanto ya no es meramente "cognitivo", adquiriendo a todos los efectos un valor «creativo» (Lupo, 2017: 113) ${ }^{54}$. Por consiguiente, en virtud de esta «desviación del concepto de irretroactividad de la norma a la sentencia» («slittamento del concetto di irretroattività dalla norma alla sentenza», Longo, 2018: 9), los jueces italianos deberán inaplicar los plazos de prescripción previstos solo para aquellos hechos ocurridos después de la primera decisión Taricco $I^{55}$.

\section{EL PRINCIPIO DE LEGALIDAD PENAL COMO LÍMITE A LA PRIMACÍA DEL DERECHO DE LA UE}

A continuación, el TJUE se detiene en el alcance y significado del principio de legalidad penal, que constituye el eje central en torno al que se desarrolla la solución del asunto Taricco. El principio de legalidad de los delitos y de las penas, con sus corolarios (previsibilidad, precisión e irretroactividad de la ley penal aplicable), es un elemento constitutivo de la identidad constitucional de los ordenamientos jurídicos nacionales y de aquella de la $\mathrm{UE}^{56}$. Se trata de un principio general del derecho de la UE, consagrado en el art. 49 de la Carta, que pertenece a las tradiciones constitucionales comunes a los Estados miembros y ha sido reconocido en los tratados internacionales en materia de protección de los derechos humanos fundamentales, en particular el art. 7 $\mathrm{CEDH}$, apdo. 1.

54 Según el A.: «L'individuazione del punto di riferimento della retroattività non nella legge, ma in una sentenza che, secondo l'opinione tradizionale sulla natura dell'attività giurisdizionale, si limita a dichiarare il significato della legge, costituisce un chiaro riconoscimento della funzione non meramente cognitiva della giurisprudenza (almeno di quella della Corte europea) ed un elemento utilizzabile dai sostenitori della creatività (sia pure limitata) della stessa» (p. 113).

55 Sentencia M.A.S y M.B., cit., apdo. 60.

56 Sobre el principio de legalidad en materia penal, se renvía ex multis a: Arroyo Zapatero (1983); Nieto Martín (1996); Pérez del Valle (2008); Silva Sánchez (2007); Tinoco Pastrana (1997). 
Del razonamiento del TJUE se deduce que tanto la Carta de los Derechos Fundamentales como las tradiciones constitucionales comunes a los Estados miembros asumen un papel determinante en la protección de los derechos fundamentales. La obligación de garantizar la percepción eficaz de los recursos financieros de la Unión no puede entrar en conflicto con el principio de legalidad penal, que en virtud de su reconocimiento en la Carta debe ser respetado por los Estados miembros cuando actúen el derecho de la UE (art. 51, apdo. 1, de la misma), como en el caso de las obligaciones de imponer sanciones penales para los delitos en materia IVA, derivadas del artículo 325 TFUE.

En esta sentencia el TJUE, modulando la doctrina Taricco I, «maximiza» la tutela de los derechos fundamentales previstos en la Carta y considerados como principios generales del derecho (art. 6 TFUE, apdo. 3), en cuanto parte de las tradiciones constitucionales comunes, los cuales prevalecen sobre los mismos tratados (Mori, 2017: 14).

En este sentido, las tradiciones constitucionales comunes adquirirían una "función complementaria» (Della Cananea, 2018: 15), constituyendo el punto de conexión entre el ordenamiento de la UE y los ordenamientos internos, tanto desde un punto de vista procedimental, en relación con el papel del reenvío prejudicial, como desde el punto de vista sustancial, en relación a su valor de "principios generales» (en este caso el principio de legalidad penal) del derecho UE.

En cuanto tradición constitucional común, el principio de legalidad es inherente a una base común, un núcleo preexistente, que ha contribuido a configurar y delinear los rasgos fundamentales de los Estados miembros, en el marco de los que a su vez se ha especificado. Se trata de un proceso circular, en el que tradiciones constitucionales comunes y tradiciones constitucionales nacionales se retroalimentan, induciendo mutaciones reciprocas. En dicho contexto, corresponde a los jueces distinguir los rasgos comunes de esta categoría y las declinaciones que asume en cada Estado miembro. En el ordenamiento italiano, por ejemplo, los requisitos de la previsibilidad, precisión e irretroactividad inherentes al principio de legalidad de los delitos y de las penas se aplican también al régimen de la prescripción de los delitos en materia IVA.

De ahí la importancia del papel del juez nacional, que tiene que comprobar si la no aplicación de las disposiciones «controvertidas» del código procesal penal italiano sobre el techo máximo de prescripción de los delitos puede producir una situación de incertidumbre en el ordenamiento jurídico italiano, que contrastaría con el principio de determinación del régimen de 
prescripción aplicable. De ser así, el juez nacional no está obligado a dejar sin aplicación las disposiciones del Código Penal controvertidas ${ }^{57}$.

Por lo tanto, cuando el juez nacional considere que la obligación de no aplicar las disposiciones del Código Penal vulnera el principio de legalidad penal, deberá inaplicar dichas disposiciones nacionales, incumpliendo tal obligación, y ello aunque su respeto permitiera subsanar una situación nacional opuesta al derecho de la Unión ${ }^{58}$.

Por todo ello, el art. 325 TFUE, apdos. 1 y 2, deberá interpretarse en el sentido de que obliga al juez nacional a no aplicar, en el marco de un procedimiento penal que se refiere a infracciones relativas al impuesto sobre el valor añadido, disposiciones internas en materia de prescripción comprendidas en el derecho material nacional que impiden la imposición de sanciones penales efectivas y disuasorias en un número considerable de casos de fraude grave que afecten a los intereses financieros de la Unión Europea o que establecen en el caso de fraudes que afecten a dichos intereses financieros plazos de prescripción más cortos que en el caso de fraudes que afecten a los intereses financieros del Estado miembro de que se trate, a menos que la mencionada inaplicación implique una violación del principio de legalidad de los delitos y las penas, debido a la falta de precisión de la ley aplicable o debido a la aplicación retroactiva de una legislación que impone condiciones de exigencia de responsabilidad penal más severas que las vigentes en el momento de la comisión de la infracción.

Dicho planteamiento, que remite a los jueces comunes la aplicación/ inaplicación, dependiendo de las características particulares del caso concreto sometido a juicio, de la doctrina Taricco I o de la excepción prevista en la Taricco II, pretende reforzar sin duda su papel como «jueces europeos».

\section{LA ACTITUD CENTRÍPETA DE LA CORTE COSTITUZIONALE}

Y por último, en cuanto a los efectos de la sentencia M.A.S. y M.B., es oportuno hacer referencia no solo a la respuesta de la Corte costituzionale en la sentencia 115/2018, sino también a la actitud que, en general, esta pretende asumir en el «diálogo jurisdiccional europeo». La Consulta pone momentáneamente fin a esta diatriba. Sin embargo, dicha decisión marca solo aparentemente el epílogo de este controvertido asunto. Como ya se ha dicho, en realidad, no se han resuelto los problemas que lo han originado.

57 Sentencia M.A.S y M.B., cit., apartado 58.

58 Sentencia M.A.S. y M.B., cit., apartado 61. 
La posición de la Corte costituzionale en la sentencia 115/2018 sigue plenamente la corriente jurisprudencial, que desde la sentencia 183/1973 había deducido la existencia de los contralímites (Cartabia, 1995: 114), individualizando el fundamento constitucional de la primacía del derecho UE en el art. 11 Const. it. Atendiendo a dicho precepto, "Italia permite, en condiciones de igualdad con otros Estados, las limitaciones de soberanía necesarias para un ordenamiento que asegure la paz y la justicia entre las Naciones», promoviendo y favoreciendo las organizaciones internacionales instituidas a tales efectos, al fin de «definir la apertura de Italia a las más comprometidas formas de colaboración y organización internacional $\aleph^{59}$. Según la Consulta estas limitaciones no pueden permitir a los órganos de la Unión violar los principios fundamentales de los ordenamientos constitucionales o los derechos inalienables de la persona humana. En dichas hipótesis, la Corte costituzionale estaría legitimada a intervenir, enjuiciando la compatibilidad del tratado con dichos preceptos fundamentales ${ }^{60}$.

Estos principios fueron reafirmados con fuerza en la sentencia 238/2014, en la que la Consulta, por primera vez, aplicó los contralímites ante una norma de derecho internacional consuetudinario; la sentencia 49/2015 ${ }^{61}$, en la que delimitó la función del CEDH en el ámbito del ordenamiento italiano; y el auto 24/2017, en el ámbito del asunto Taricco, en relación a la primacía y a los efectos directos del derecho europeo.

Además, poco antes de la publicación de la Taricco II, la Corte costituzionale tuvo que volver a afrontar el espinoso tema de las relaciones entre derecho interno-derecho de la Unión en la sentencia 269/2017, de 7 de noviembre de $2017^{62}$, en la que hizo referencia a este pronunciamiento con un tono de desafío. Al respecto, se afirmó que en el caso de que «la violación de un derecho de la persona afecte, al mismo tiempo, tanto a las garantías protegidas por la Constitución italiana, como a las codificadas por la Carta de los derechos de la Unión, como ocurrió con respecto al principio de legalidad de los delitos y de las penas (TJUE, Gran Sala, sentencia de 5 de diciembre de 2017, en el asunto C-42/17, M.A.S y M.B. ${ }^{63}$, [...] la Corte enjuiciará

59 Corte costituzionale, sent. n. 183/1973, punto 5 del Cons. in dir.

60 Ibid., punto 9 del Cons. in dir.; y Corte costituzionale, sent. n. 170/1984, punto 7 del Cons. in dir.

61 Corte cost, sent. 49/2015, dep. 26.03.2015.

62 Corte cost., sent. 269/2017, 7.11.2017, dep. 14.12.2017.

63 Corte costituzionale, sent. 269/2017, cons. in dir. n. 5.2. En el citado fundamento jurídico se afirma también que la Carta constituye parte del derecho de la UE y está dotada de caracteres peculiares por su huella típicamente constitucional: «Fermi restando i principi del primato e dell'effetto diretto del diritto dell'Unione europea come sin qui 
atendiendo a los parámetros internos y eventualmente a aquellos europeos (ex arts. 11 y 117 Const. $)^{64}[\ldots]$ al fin de asegurar que los derechos garantizados por la mencionada Carta de los derechos sean interpretados en armonía con las tradiciones constitucionales», a las que hacen reenvío los arts. 6 del TUE y 52.4 de la Carta como fuentes relevantes en dicho ámbito ${ }^{65}$.

Se trata de una actitud caracterizada por una evidente tendencia centrípeta (Faraguna, 2018: 7), tendente a la recentralización del control de legitimidad constitucional respecto al movimiento centrífugo, que denota el intento la Corte costituzionale de reforzar la perspectiva nacional de protección de los derechos fundamentales, renacionalizándola, y de erigirse a todos los efectos a "guardián de los contra-límites», es decir de la «identidad constitucional italiana» frente a intromisiones indebidas por parte de la primacía del derecho de la UE (Anzon Demmig, 2018: 1).

La Corte costituzionale vuelve a confirmar esta corriente jurisprudencial también en la sentencia 115/2018, en la que, teniendo en cuenta el esfuerzo interpretativo del TJUE, decide no aplicar los contralímites, aunque en definitiva afirma que la regla Taricco I sobre el cálculo de la prescripción para los delitos en materia IVA no tiene cabida en el ordenamiento italiano.

En su opinión, tras la STJUE en el asunto M.A.S y M.B., el supuesto contraste entre la regla Taricco $I$ y los principios supremos del ordenamiento constitucional, y especialmente el principio de legalidad en materia penal, reconocido en el art. 25.2 Const. it., habría desaparecido, atendiendo a que el art. 325 TFUE (tal y como fue interpretado por el TJUE en 2015) no es aplicable ni a los hechos anteriores al 8 de septiembre de 2015 (y por lo tanto en los juicios a quibus) ni cuando el juez nacional constate la violación del principio de legalidad en materia penal ${ }^{66}$.

consolidatisi nella giurisprudenza europea e costituzionale, occorre prendere atto che la citata Carta dei diritti costituisce parte del diritto dell'Unione dotata di caratteri peculiari in ragione del suo contenuto di impronta tipicamente costituzionale. I principi e i diritti enunciati nella Carta intersecano in larga misura i principi e i diritti garantiti dalla Costituzione italiana (e dalle altre Costituzioni nazionali degli Stati membri)».

64 Ibid.

65 Ibid.

66 Según el comunicado de la Corte Constitucional, Roma, de 10 de abril de 2018: «I giudici non sono tenuti ad applicare la "regola Taricco" sul calcolo della prescrizione, stabilita dalla Corte di Giustizia Ue con la sentenza dell'8 settembre 2015 per i reati in materia di Iva. Pertanto, anche per questi reati, rimangono applicabili gli articoli 160, ultimo comma, e 161 del Codice penale. La Corte costituzionale, riunita oggi in camera di consiglio, ha infatti dichiarato infondate le questioni di legittimità costituzionale dell'articolo 2 della legge di autorizzazione alla ratifica del Trattato di Lisbona 
En este sentido, la sentencia M.A.S. y M.B. habría permitido eliminar los perfiles de incompatibilidad con la prohibición de retroactividad in malam partem de la ley penal ${ }^{67}$, con arreglo a dicho esquema: los delitos de fraude que afectan a los intereses UE realizados después del 8 de septiembre de 2015 tendrán un plazo de prescripción más largo; en cambio, para los delitos cometidos antes de dicha fecha y para los procesos todavía pendientes se seguirán aplicando las "controvertidas» disposiciones del Código Penal italiano.

Sin embargo, según la Corte costituzionale, la regla Taricco no puede ser aplicada en el ordenamiento italiano porque sigue siendo contraria al principio de determinación ${ }^{68}$. Este "déficit de precisión» afectaría tanto al art. 325, párr. 1 y 2, puesto que de su formulación no se podía prever dicha regla, así como esta regla en sí, cuando hace referencia al requisito del «número considerable de casos» ${ }^{69}$.

Corresponderá de forma exclusiva a la Corte costituzionale, en cuanto «guardián de los contra-límites» (Manes, 2017: 9), verificar el respeto de los principios supremos del orden constitucional, y en particular de los derechos inalienables de la persona, que la sentencia Taricco II había remitido en términos generales a los jueces comunes ${ }^{70}$. Estos, cuando tengan una duda sobre la conformidad de una normativa nacional que incorpora una norma de derecho de la UE, tendrán que dirigirse a la Corte costituzionale, interponiendo una cuestión de legitimidad.

(n. 130/2008), là dove dà esecuzione all'articolo 325 del Trattato sul funzionamento dell'Ue (TFUE) come interpretato dalla Corte di Giustizia con la "sentenza Taricco". Le questioni erano state sollevate dalla Cassazione e dalla Corte d'appello di Milano sul presupposto che la "regola Taricco" fosse senz'altro applicabile nei giudizi in corso, in contrasto con i principi supremi dell'ordinamento costituzionale, in particolare con il principio di legalità in materia penale (articolo 25 della Costituzione). Secondo i giudici costituzionali, però, questo presupposto è caduto con la sentenza "Taricco bis" del 5 dicembre 2017, in base alla quale l'articolo 325 TFUE (come interpretato dalla Corte di Giustizia nel 2015) non è applicabile né ai fatti anteriori all' 8 settembre 2015 (e dunque nei giudizi a quibus) né quando il giudice nazionale ravvisi un contrasto con il principio di legalità in materia penale».

67 Corte cost., sent. 115/2018, cons. in dir. n. 7.

68 Ibid., cons. in dir. n. 10: «Indipendentemente dalla collocazione dei fatti, prima o dopo l'8 settembre 2015, il giudice comune non può applicare loro la "regola Taricco", perché essa è in contrasto con il principio di determinatezza in materia penale, consacrato dall'art. 25, secondo comma, Cost.».

69 Ibid., cons. in dir. n. 11.

70 La Corte Costituzionale se expresaba en tal sentido ya en la ord. n. 24/2017, cons. in dir. n. 7. 


\section{ALGUNAS REFLEXIONES EN TORNO AL ASUNTO TARICCO}

En definitiva, tras este análisis de la «saga Taricco» se pueden extraer algunas conclusiones. Ante todo, la trascendencia de este asunto ha sido sobrestimada y en cierta medida instrumentalizada. Para la doctrina italiana esta era la ocasión óptima para instar a la Corte costituzionale a elevar su voz autorizada, en nombre de una supuesta identidad constitucional nacional vulnerada (la prescripción como instituto de derecho penal sustantivo), y aplicar finalmente los contralímites. De tal forma, se estaba buscando el enfrentamiento abierto con el TJUE, a fin de reivindicar la autonomía de la Consulta y su rol en el ámbito del ordenamiento interno, poniendo fin a la primacía incondicionada del derecho de la UE.

Todo esto, por supuesto, no elimina las críticas que, con razón, se han formulado contra la sentencia Taricco I y los problemas reales de aplicación que esta presenta. La inaplicación in malam partem por parte del juez común de las disposiciones penales controvertidas, aunque pretendía evitar espacios de impunidad y, de camino, eliminar el contraste con el derecho de la UE, planteaba un conflicto con los principios fundamentales del ordenamiento italiano.

Asimismo, se remite la evaluación acerca de la oportunidad de proceder en tal sentido a criterios como el de la existencia del «número considerable» y de la "gravedad de los fraudes», sin especificar el umbral mínimo. Tales requisitos podrían resultar, en determinados supuestos, demasiado subjetivos y personales, y contrarios a los preceptos fundamentales del derecho penal italiano.

Afortunadamente, la Corte costituzionale actuó con prudencia y, consciente de los efectos que habría desencadenado la activación inmediata de los contralímites, decidió con un estratégico reenvío prejudicial poner un ultimátum al TJUE, que no tuvo más remedio que ceder y reorientar parcialmente su primera decisión. La oposición del contralímite del principio de legalidad en materia penal ex art. 25.2 Const. it. por parte de la Consulta muy probablemente hubiera desencadenado un efecto dominó, incentivando a los demás tribunales constitucionales de los Estados miembros a enfrentarse a la primacía del derecho UE. Y el TJUE tenía que evitar que esto ocurriera.

De este asunto, por lo tanto, se deduce ante todo la necesidad de aclarar cuáles son los principios fundamentales constituyentes del núcleo duro del patrimonio constitucional nacional y, sobre todo, hasta qué punto la UE puede incidir en ellos. La definición de tales categorías se hace aún más compleja por los efectos expansivos del derecho de la UE y de la jurisprudencia del 
TJUE en las principales categorías del derecho penal, sustantivo y procesal ${ }^{71}$. Dichos ámbitos han asumido progresivamente una nueva dimensión «supranacional», que ha impuesto su reformulación en clave europea.

En dicho contexto, los tribunales constitucionales nacionales podrían servirse del potente instrumento de los contralímites para oponerse a la primacía incondicionada del derecho de la UE, frenando la fuerza rompedora del TJUE. Esta arma, sin embargo, debería ser accionada con cautela, puesto que la activación de los mismos podría crear una fractura difícilmente sanable en el proceso de integración europea. El mismo TJUE en la sentencia M.A.S. y M.B., dando (aparentemente) marcha atrás, parece haberse dado cuenta de las potencialidades de este instrumento sobre todo si aplicado por un Tribunal constitucional tan autorizado como la Corte costituzionale italiana. De hecho, el Tribunal de Justicia esquiva en su argumentación el concepto de contralímite. No se atreve ni a mencionar esta categoría; sin embargo, la usa silenciosamente al considerar el principio de legalidad penal como límite a la primacía del derecho UE, en cuanto principio general fruto de las tradiciones constitucionales comunes a los Estados miembros.

Por otro lado, no se puede desconocer la importancia que esta saga ha tenido en el diálogo jurisdiccional europeo y, en general, en la construcción de un espacio común de justicia, basado en la cooperación judicial en materia penal, en el que el TJUE está destinado a asumir un papel de fundamental importancia. La sentencia Taricco I, al margen de todos sus defectos, ha puesto de relieve, por un lado, el rol determinante que el TJUE está asumiendo en la definición de dicho espacio, un papel que reenvía a aquel desempeñado por el TEDH en las sentencias piloto; y por otro, el miedo de los tribunales constitucionales nacionales, sobre todo de algunos, de perder el rol hasta el momento desempeñado en el ámbito de sus ordenamientos internos.

En este sentido, no se puede soslayar que el TJUE ha mostrado abiertamente los fallos no solo de la normativa italiana en materia de prescripción

71 Según Manacorda (2018: 7-8), «The conflict between the two courts, which was considered by most commentators as one which threatened the future of European Criminal Law is, in our view, an element that contributed to strengthening the (highly problematic) legitimation of the latter. Human rights allow for, to a certain extent, a judicial dialogue between the ECJ and the Italian Constitutional Court. A risk has transformed into an opportunity and has produced a positive outcome. The specificities of the domestic criminal law enshrined in the Constitution deserve to be taken into account and considered in balance with the effectiveness of EU law. Moreover, they must have a priority when - as in this case — fundamental constitutional guarantees are at stake. Criminal law, thanks to this unfortunate conflict, demonstrated that it cannot be treated as any other branch of the legal order». 
que ha sido reiteradamente tachada de incompatible con el derecho de la Unión, sino también los problemas estructurales de la maquinaria judicial de este país que no consigue garantizar el derecho a un proceso sin dilaciones indebidas y, al contrario, asegura la impunidad de autores de delitos graves. Este, según quien escribe, constituye el verdadero problema que pone encima de la mesa el caso Taricco y que, sin embargo, parece haber pasado en un segundo plano respecto a la disputa Corte costituzionale/TJUE.

En cambio, en lo que concierne a la función de los tribunales constitucionales nacionales, estos no han perdido su función de garantes de los principios y valores superiores del ordenamiento interno. Sin embargo, es cierto que el desempeño de sus funciones está condicionado por el espacio de regulación supranacional. La protección de los derechos fundamentales ya no corresponde de forma exclusiva a los Estados, sino que es una tarea compartida con los órganos jurisdiccionales supranacionales.

Y por último, se observa que, en realidad, no se ha producido un verdadero diálogo. Aunque sea cierto que la sentencia Taricco II haya evitado la aplicación de los contralímites, tanto el TJUE como la Corte costituzionale han mantenido sus posiciones de partida. La sentencia M.A.S. y M.B., en realidad, no establece una verdadera excepción a la regla Taricco y a la primacía del derecho de la Unión. En dicho pronunciamiento el TJUE adopta una actitud que se podría definir ambigua. A primera vista, parece que este haya dado un paso atrás, pero en realidad intenta reinterpretar el principio de legalidad en materia penal en clave europea, con el objeto de resaltar su papel de garante último ya no solo de los intereses financieros de la UE, sino también de los derechos fundamentales en el espacio europeo de justicia penal post-Lisboa. El caso Taricco, por lo tanto, refleja esta nueva realidad, en la que el TJUE ha asumido una función de control/límite del derecho penal (sustantivo y procesal) de los Estados miembros.

Por otra parte, la Corte costituzionale afirma la inaplicabilidad de la regla Taricco $I$ en el ordenamiento italiano porque es contraria al principio de determinación, legitimando por consiguiente la aplicación de los art. 160 y 161 del Código Penal italiano, los cuales han sido calificados de forma reiterada por el TJUE de incompatibles con el derecho UE; no hace referencia en ningún momento a los problemas estructurales que afectan al sistema de justicia penal italiano; y parece preocupada solo por subrayar su rol de garante de los derechos fundamentales.

En todo esto, el aspecto más preocupante es que este tipo de conflictos está destinados a producirse cada vez más. Tanto el TJUE como los órganos jurisdiccionales de los Estados miembros tendrán que aprender a gestionarlos, mediante ponderaciones equilibradas e intentando respetar las respectivas esferas de autonomía. 


\section{Bibliografía}

Amalfitano C. (2015). Da una impunità di fatto a una imprescrittibilità di fatto della frode in materia di imposta sul valore aggiunto? SIDIBlog [blog], 15-9-2015. Disponible en: https://bit.ly/2kR3yFz.

_ (2017). La vicenda Taricco nuovamente al vaglio della Corte di giustizia: qualche breve riflessione a caldo. Eurojust.it. Disponible en: https://bit.ly/2M20d32.

Anagnostaras, G. (2016). Mutual confidence is not blind trust! Fundamental rights protection and the execution of the European arrest warrant: Aranyosi and Căldăraru. Common Market Law Review, 53 (6), 1675-1704.

Anzon Demmig, A. (2017). La Corte costituzionale è ferma sui «controlimiti», ma rovescia sulla Corte europea di Giustizia l'onere di farne applicazione bilanciando esigenze europee e istanze identitarie degli Stati membri. Osservatorio AIC, 2, 1-23.

(2018). La Corte riprende il proprio ruolo nella garanzia dei diritti costituzionali e fa un altro passo avanti a tutela dei "controlimiti». Forumcostituzionale.it, 1-6. Disponible en: https://bit.ly/2sBcsvd.

Arroyo Zapatero, L. A. (1983). Principio de legalidad y reserva de ley en materia penal. Revista Española de Derecho Constitucional, 3 (8), 9-46.

Arzoz Santisteban, X. (2016). Karlsruhe rechaza la Doctrina Melloni del Tribunal de Justicia y advierte con el control de la identidad constitucional (comentario a la Sentencia del Tribunal Constitucional Federal Alemán de 15 de diciembre de 2015, 2 BVR 2735/14). Civitas. Revista Española de Derecho Europeo, 58, 109-141.

Balaguer Callejón, F. (2017). Primato del diritto europeo e identità costituzionale nell'esperienza spagnola. En A. Bernardi (cur.). I controlimiti: primato delle norme europee e difesa dei principi costituzionali: Atti del Convegno del Dottorato di ricerca "Diritto dell'Unione europea e ordinamenti nazionali» del Dipartimento di Giurisprudenza dell'Università di Ferrara. Ferrara, 7-8 aprile 2016 (pp. 113135). Napoli: Jovene.

Bassini, M. (2016). Prescrizione e principio di legalità nell'ordine costituzionale europeo. Note critiche alla sentenza Taricco. Consulta Online, 2016-1, 94-113. Disponible en: http://www.giurcost.org/studi/bassini.pdf.

Pollicino O. (2017). The Taricco Decision: A Last Attempt to Avoid a Clash between EU Law and the Italian Constitution. Verfassungsblog.de [blog], 28-12017. Disponible en: https://bit.ly/2M24bbW.

Bernardi, A. (cur.). (2017). I controlimiti: primato delle norme europee e difesa dei principi costituzionali: Atti del Convegno del Dottorato di ricerca "Diritto dell'Unione europea e ordinamenti nazionali» del Dipartimento di Giurisprudenza dell'Università di Ferrara. Ferrara, 7-8 aprile 2016. Napoli: Jovene.

- Cupelli, C. (cur.) (2017). Il caso Taricco e il dialogo tra le Corti. L'ordinanza 24/2017 della Corte costituzionale, Napoli: Jovene. 
Besselink, L. (2014). The Parameters of Constitutional Conflict after Melloni. European Law Review, 39, 531-552.

Bin, R. (2016). Taricco, una sentenza sbagliata: come venirne fuori? Diritto Penale Contemporaneo, 4-7-2016. Disponible en: https://bit.ly/2kTEH49.

— (2017). Taricco: aspettando Godot, leggiamo Yves Bot. Forumcostituzionale.it, 1-4. Disponible en: https://bit.ly/2JXirp6.

— (2018). Taricco Tango. Quale sarà il prossimo passo? Forumcostituzionale.it, 1-4. Disponible en: https://bit.ly/2MHbaqU.

Calvano, R. (2016). La Corte costituzionale e i 'Controlimiti' 2.0. Federalismi.it, 1-19. Disponible en: https://bit.ly/2xU0nXk.

Cartabia, M. (1995). Principi inviolabili e integrazione europea. Milano: Giuffrè.

Chessa, O. (2018). Forum di discussione La saga Taricco a una svolta: in attesa della decisione della Corte costituzionale (II parte). Rivista di diritti comparati. 1, 3-9.

Civello, G. (2015). La sentenza «Taricco» della Corte di Giustizia UE: contraria al Trattato la disciplina italiana in tema di interruzione della prescrizione del reato. Archiviopenale. it, 3, 2-17.

Cupelli, C. (2017). La Corte costituzionale ancora non decide sul caso taricco, e rinvia la questione alla Corte di giustizia. Diritto Penale Contemporaneo, 30, 199-244.

Della Cananea, G. (2018). Le tradizioni costituzionali comuni prese sul serio. Forum di discussione La saga Taricco a una svolta: in attesa della decisione della Corte costituzionale (II parte). Rivista di diritti comparati, 1, 9-15.

Dickmann, R. (2014). Il «Diritto al giudice» di cui all'art. 24 Cost. come principio supremo e limite al diritto internazionale generalmente riconosciuto. Federalismi.it, 22, 1-22. Disponible en: https://bit.ly/2JfaBXs.

Eusebi, L. (2015). Nemmeno la Corte di Giustizia dell'Unione Europea può erigere il giudice a legislatore. Diritto Penale Contemporaneo, 2, 1-8.

Faggiani, V. (2014). Verso la definizione di uno «standard comune» di protezione del diritto a un processo equo (gli effetti della «sentenza Melloni» nello spazio europeo di giustizia penale). Federalismi.it, 19, 1-28.

- (2016). Ius puniendi europeo v. controlimiti. Riflessioni a margine del caso Taricco. Studi sull'integrazione europea, 2/3, 509-532.

- (2017a). Los derechos procesales en el espacio europeo de justicia penal. Técnicas de armonización. Aranzadi: Cizur Menor (Navarra).

— (2017b). Lo strategico rinvio pregiudiziale della Consulta sul caso Taricco». Osservatorio AIC, 1, 1-11.

Faraguna, P. (2014). Corte costituzionale contro Corte internazionale di giustizia: i controlimiti in azione. Forumcostituzionale.it, 1-4. Disponible en: https://bit. ly/21 mwfvA.

_ (2016). Alla ricerca dell'identità costituzionale tra conflitti giurisdizionali e negoziazione politica. Costituzionalismo.it., 3, 197-254. 
- (2017). The Italian Constitutional Court in re Taricco: «Gauweiler in the Roman Campagna». verfassungsblog.de [blog], 31-1-2017. Disponible en: https:// bit.ly/2JffFet.

(2018). Forum di discussione. La saga Taricco a una svolta: in attesa della decisione della Corte costituzionale (I parte). Rivista di diritti comparati, 1, 3-8.

Fichera, M. (2018). Forum su "La saga Taricco a una svolta: in attesa della decisione della Corte costituzionale. Rivista di diritti comparati, 8, 8-15.

Guazzarotti, A. (2017). I paradossi della vicenda Taricco. La sovranità limitata in favore dell'UE e 'controlimitata' in favore della Costituzione. laCostituzione.info.

Kostoris, R. E. (2017). La Corte Costituzionale e il caso Taricco, tra tutela dei 'controlimiti' e scontro tra paradigmi. Diritto Penale Contemporaneo, 3, 1-15.

Longo, A. (2018). Taricco-bis: un dialogo senza comunicazione. Archiviopenale.it, 1, $1-19$.

Luciani, M. (2016). Il brusco risveglio. I controlimiti e la fine mancata della storia costituzionale. Rivista Aic.it, 2, 1-20.

- (2017). Intelligenti pauca. Il caso Taricco torna (catafratto) a Lussemburgo. Osservatorio AIC, 1, 1-11.

Lupo, E. (2016). La Primauté deldiritto dell'UE e l'ordinamento penale nazionale. Riflessioni sulla sentenza Taricco. Diritto Penale Contemporaneo, 1, 1-15.

— (2017). La sentenza europea c.d. taricco-bis: risolti i problemi per il passato, rimangono aperti i problemi per il futuro. Diritto Penale Contemporaneo, 12, 109-121.

Maiello V. (2016). Prove di resilienza del nullum crimen: Taricco versus controlimiti. Cassazione penale, 56 (3), 1250-1259.

Manacorda, S. (2013). Dalle Carte dei diritti a un diritto penale «à la carte»? Note a margine delle sentenze Fransson e Melloni della Corte di Giustizia. Diritto Penale Contemporaneo, 3, 1-14.

- (2018). The Taricco saga: A risk or an opportunity for European Criminal Law? New Journal of European Criminal Law, 9 (1), 4-11.

Manes, V. (2016). La «svolta» Taricco e la potenziale «sovversione di sistema»: le ragioni dei controlimiti. Diritto Penale Contemporaneo, 1-26.

- (2017). La Corte muove e, in tre mosse, dà scacco a "Taricco". Note minime all'ordinanza della Corte Costituzionale n. 24 del 2017. Diritto Penale Contemporaneo, 1-14.

- (2018). Some lessons from the Taricco saga. New Journal of European Criminal Law, 9 (1), 12-17.

Marcolini, S. (2016). La prescrizione del reato tra diritto e processo: dal principio di legalità sostanziale a quello di legalità processuale. Cassazione penale, 56 (1), 362-374.

Martín Rodríguez, P. J. (2013). Crónica de una muerte anunciada: comentario a la Sentencia del Tribunal de Justicia (Gran Sala), de 26 de febrero de 2013, Stefano Melloni, C-399/11. Revista General de Derecho Europeo, 30, 1-45. 
- (2016). La emergencia de los límites constitucionales de la confianza mutua en el espacio de libertad, seguridad y justicia en la Sentencia del Tribunal de Justicia Aranyosi y Căldăraru. Revista de Derecho Comunitario Europeo, 55, 859-900.

Montanari, L. (2018). Forum di discussione La saga Taricco a una svolta: in attesa della decisione della Corte costituzionale (II parte). Rivista di diritti comparati, $1,16-23$.

Mori, P. (2017). Taricco II o del primato della Carta dei diritti fondamentali e delle tradizioni costituzionali comuni agli Stati membri. Osservatorio Europeo DUE, 4, 1-18.

Nieto Martín, A. (1996). Fraudes comunitarios derecho penal económico europeo. Barcelona:Wolters Kluwer.

Nisticò, M. (2018). Taricco II: il passo indietro della Corte di giustizia e le prospettive del supposto dialogo tra le Corti. Osservatorio Costituzionale AIC, 1, 1-6.

Nowag, J. (2016), EU law, constitutional identity, and human dignity: A toxic mix? Bundesverfassungsgericht: Mr R. Common Market Law Review, 53 (5), 14411453.

Pérez del Valle, C. (2008). Derecho penal europeo, principio de legalidad y principio de proporcionalidad. Indret: Revista para el Análisis del Derecho, 4, 1-24.

Repetto, G. (2017). Una ragionevole apologia della supremacy. In margine all'ordinanza della Corte costituzionale sul caso Taricco. Rivista di diritti comparati, 1. Disponible en: https://bit.ly/2sM2Lt0.

Rossi, F. (2015). La sentenza Taricco della Corte di Giustizia e il problema degli obblighi di disapplicazione in malam partem della normativa penale interna per contrasto con il diritto UE. Diritto penale e processo, 12, 1564-1571.

Ruggeri, A. (2013). La Corte di giustizia e il bilanciamento mancato (a margine della sentenza Melloni). Il diritto dell'Unione Europea, 2, 399-408.

(2014). La Corte aziona l'arma dei «controlimiti» e, facendo un uso alquanto singolare delle categorie processuali, sbarra le porte all'ingresso in ambito interno di norma internazionale consuetudinaria (a margine di Corte cost. n. 238 del 2014). Diritti comparati. Disponible en: https://bit.ly/2kSXtZa.

(2016). Primato del diritto sovranazionale versus identità costituzionale? (Alla ricerca dell'araba fenice costituzionale: i «controlimiti»). Forumcostituzionale.it, 1-17. Disponible en: https://bit.ly/2JukvDJ.

(2017a). Ultimatum della Consulta alla Corte di giustizia su Taricco, in una pronunzia che espone, ma non ancora oppone, i controlimiti (a margine di Corte cost. n. 24 del 2017). Consulta online, 1, 81-88. Disponible en: https:// bit.ly/2M1NjlH.

- (2017b). La Corte di giustizia porge un ramoscello di ulivo alla Consulta su Taricco e resta in fiduciosa attesa che legislatore e giudici nazionali si prendano cura degli interessi finanziari dell'Unione (a prima lettura della sentenza della Grande Sezione del 5 dicembre 2017). Rivista di diritti comparati, 3, 1-9.

Salcuni, G. (2015). Legalità europea e prescrizione del reato. Archiviopenale.it, 3, $1-15$. 
Sarmiento Ramírez Escudero, D. (2013). Who's afraid of the Charter? The Court of Justice, national courts and the new framework of fundamental rights protection in Europe. Common Market Law Review, 50 (5), 1267-1304.

- (2015). The scope of application of EU Law and national criminal law: some thoughts on Taricco (C-105/14). Despite our Differences [blog], 8-9-2015. Disponible en: https://bit.ly/2sJkDVy.

— (2018). Adults in the (Deliberation) Room. A comment on M.A.S. Forumcostituzionale.it, 1-4. Disponible en: https://bit.ly/2kRb03v.

Silva Sánchez, J. M. (2007). Principio de legalidad y legislación penal europea: ¿una convergencia imposible? En L. Arroyo Zapatero, A. Nieto Martín y A. Muñoz de Morales Romero (coords.). El derecho penal de la Unión Europea: situación actual y perspectivas de futuro (pp. 113-135). Ciudad Real: Universidad de Castilla-La Mancha.

Tega, D. (2017). Narrowing the Dialogue: The Italian Constitutional Court and the Court of Justice on the Prosecution of VAT Frauds. I-Connet [blog], 14-22017. Dioponible en: https://bit.ly/2HpN7c7.

Tinoco Pastrana, A. (1997). Principio de legalidad y legislación penal europea: ¿una convergencia imposible? Cuadernos de política criminal, 63, 711-730.

Torres Pérez, A. (2014). Melloni in three acts: from dialogue to monologue. European Constitutional Law Review, 10 (2), 308-331.

Viganò, F. (2015a). Prescrizione e reati lesivi degli interessi finanziari dell'UE: la Corte d'appello di Milano sollecita la Corte costituzionale ad azionare i «controlimiti». Diritto Penale Contemporaneo.

(2015b). Disapplicare le norme vigenti sulla prescrizione nelle frodi in materia di iva? Primato del diritto UE e nullum crimen sine lege in una importante sentenza della Corte di giustizia. Diritto Penale Contemporaneo, 1-16.

— (2016). Il caso Taricco davanti alla Corte costituzionale: qualche riflessione sul merito delle questioni, e sulla reale posta in gioco. Diritto Penale Contemporaneo, $1-35$.

(2018). Melloni overruled? Considerations on the "Taricco II» judgment of the Court of Justice. New Journal of European Criminal Law, 9 (1), 18-23. 